\title{
SEPARATED OIL-WATER FLOWS WITH DRAG REDUCING POLYMERS
}

\section{Lawrence C. EDOMWONYI-OTU ${ }^{+1}$, and Panagiota ANGELI*}

Department of Chemical Engineering, University College London, Torrington Place, London, WC1E 7JE, UK

${ }^{+}$Corresponding author: uceclce@ucl.ac.uk, *p.angeli@ucl.ac.uk

${ }^{1}$ Current address: Department of Chemical and Petroleum Engineering, Delta State University, Abraka, Nigeria.

\begin{abstract}
The effects on velocity and turbulent properties of drag reducing polymers added in the water phase of oil-water flows were studied with Particle Image Velocimetry (PIV). The experiments were performed in separated horizontal oil-water flows in an acrylic pipe with an internal diameter of $14 \mathrm{~mm}$. The test fluids were tap water $\left(1.0 \mathrm{mPas}\right.$, density $\left.=1000 \mathrm{~kg} / \mathrm{m}^{3}\right)$ and a middle distillate oil (Exxsol D140; viscosity $=5.5 \mathrm{mPas}$, density $=828 \mathrm{~kg} / \mathrm{m}^{3}$ ). Magnafloc 1011 (hydrolysed copolymer of polyacrylamide and sodium acrylate, HPAM; mol. wt. $=10 \times 10^{6}$ $\mathrm{g} / \mathrm{mol}$ ) was used as drag reducing agent in the water phase at $20 \mathrm{ppm}$ concentration. Results showed that the polymer reduced frictional pressure drop at all conditions studied. The addition of polymer decreased the interface height and increased the in-situ average water velocity. The velocity profile in the water phase became more parabolic compared to the flow without polymer while the maximum velocity value increased. In addition, when polymer was added the axial stress tensor decreased close to the interface and the wall but increased in the middle of the flow, while the Reynolds and radial stress tensors reduced throughout the water phase. Two types of polyethylene oxide (PEO) polymers with different molecular weights, $5 \times 10^{6} \mathrm{~g} / \mathrm{mol}$ and $8 \times 10^{6} \mathrm{~g} / \mathrm{mol}$ were also tested. Drag reduction was found to increase with polymer molecular weight but depended also on the mechanical degradation of the polymers at high Reynolds numbers and on their ionic strength.
\end{abstract}

Keywords: Drag reducing polymers; oil-water flows; PIV; velocity profiles; Reynolds stresses

\section{INTRODUCTION}

The increasing global demand for energy necessitates the transfer of energy sources from areas of production to regions of consumption. Crude oil and its derivatives, which are still a main source of energy, are in many cases transported over long distances and mostly in pipes of varying sizes and inclinations. Often crude oil is in mixtures with water, resulting in different flow patterns that depend on pipe size and fluid properties and flowrates. Flows of aqueousorganic two phase mixtures are also very common in the process industries (Edomwonyi-Otu 
and Angeli, 2014, 2015; Barral and Angeli, 2013). The addition of very small amounts (parts per million) of some polymeric materials can significantly reduce frictional pressure drop in pipes and associated pumping requirements. This phenomenon is called drag reduction and has found extensive applications not only in crude oil transportation, but also in other areas including well drilling and hydrofracking operations, settling and filtration of oil-sand tailings, domestic heating and cooling, waste water treatment, as well as suppression of atherosclerosis and prevention of haemorrhagic shock, firefighting (Le Brun et al., 2016; Abubakar et al., 2014b; Wang et al., 2011; Al-Sarkhi, 2010). Polymers with no effect on the quality of water can be used for transportation of drinking water from treatment plants to points of use (Edomwonyi-Otu and Adelakun, 2018). The effectiveness of the drag reducing additive is usually given in terms of pressure drop reduction DR (\%):

$$
\mathrm{DR}(\%)=\frac{\Delta \mathrm{P}-\Delta \mathrm{P}_{\mathrm{P}}}{\Delta \mathrm{P}} \times 100
$$

where $\Delta \mathrm{P}$ is the pressure drop of flow without polymer and $\Delta \mathrm{P}_{\mathrm{p}}$ is the pressure drop of the flow with drag reducing agents added. Different polymers and biopolymers have been used as drag reducing agents (DRA), including polyethylene oxides (PEO), polyacrylamides (PAM), polyisobutylene (PIB), guar gum, and xanthan gum amongst others (Abdulbari et al., 2014).

Addition of polymers has also been found to affect multiphase flows, where changes in flow patterns occur in addition to frictional pressure drop reduction. When a polymer solution was added in the liquid phase of gas-liquid flows, it was found that the region of stratified flow was significantly extended, with annular and slug flows changing to stratified ones. In addition, slug frequencies were significantly reduced while disturbance waves were dampened and the liquid hold-up increased (Al-Sarkhi, 2010; Al-Sarkhi et al., 2006; Al-Sarkhi and Soleimani, 2004; Baik and Hanratty, 2003; Edomwonyi-Otu and Angeli, 2014; Edomwonyi-Otu et al., 2014; Hanratty and Al-Sarkhi, 2001; Mowla and Naderi, 2006). The delayed transition to slug flow combined with the reduction in the slug frequencies resulted in over $50 \%$ reduction in corrosion rates (Kang et al., 1998).

In oil-water flows, polymers have mainly been added in the water phase, where they extended the stratified flow region, similar to gas-liquid flows. Patterns such as rivulet, dual continuous and annular changed, in many cases, to stratified flows. Dispersed flows changed to dual continuous while in some oil-in-water dispersed flows the drop size increased. In stratified flows the interface height changed while interfacial waves were dampened and their length and celerity increased (Edomwonyi-Otu et al., 2014, 2015; Abubakar et al., 2015; Al-Wahaibi et al., 
2012, 2007; Al-Yaari et al., 2012, 2009). The drag reduction phenomenon and the flow pattern changes are generally attributed to changes in turbulence structure caused by the addition of polymers.

Experimentally, the velocity profiles and turbulence characteristics in single and multiphase flows have been studied using techniques such as particle image velocimetry (PIV), particle tracking velocimetry (PTV), and laser Doppler velocimetry/anemometry (LDV/LDA). Particle image velocimetry (PIV) in particular offers whole field, instantaneous velocity measurements and has been used extensively in single and in some cases in two phase flows (Chinaud et al., 2017; Morgan et al., 2017; Birvalski et al., 2014, 2013; Adrian and Westerweel, 2011; Chaouki et al., 1997; Westerweel, 1997; Zhou et al., 2013). These techniques have also been applied in some cases to the investigation of velocity and turbulence profiles in flows with drag reducing polymers (Edomwonyi-Otu et al., 2015; Zadrazil et al., 2012; Gyr and Bewersdorff, 1995; Virk, 1975). Wei and Willmarth (1992) used LDV to study velocity fields in channel flows with PEO added in water. They found that the polymer changed the turbulence structure with the radial turbulence intensity decreasing and the axial one increasing. The authors argued that while the energy in the radial direction is suppressed over all frequencies, in the axial direction it is redistributed from the high to the low frequencies. Den Toonder et al. (1997) studied drag reduction, when $20 \mathrm{ppm}$ of Superfloc A110 was added in water, both numerically (DNS simulations) and experimentally using LDV. They found that the radial root mean square (RMS) velocity decreased while the peak of the axial RMS velocity profile increased and shifted away from the wall. The turbulent energy in the axial direction redistributed from small to large scales, while in the radial direction it was dampened over the whole pipe cross section, particularly in the near-wall region. A mechanism was proposed for drag reduction based on the viscous anisotropic effects introduced by the extended polymeric chains on the turbulence structure. From their numerical simulations, they found that the elasticity of the polymeric chains also seemed to be important, with large elasticity increasing the drag reduction and vice versa.

Warholic et al. (2001) studied drag reduction in water flows with Percol 727 (a copolymer of polyacrylamide and sodium acrylate) using PIV. In the polymeric flows, there was drastic reduction or even elimination of the ejections of low momentum fluid close to the wall to the bulk flow, which is characteristic of Newtonian flows. They also found a reduction of both the Reynolds and radial turbulent stresses when polymer was added. At maximum drag reduction, it was possible to have turbulent flows with zero Reynolds stresses. Zadrazil et al. (2012) used 3 
different molecular weight polyethylene oxide (PEO) polymers in water in a $25.4 \mathrm{~mm}$ ID pipe to study drag reduction with PIV. They observed that drag reduction is accompanied by the appearance of randomly formed and non-stationary thin filament-like regions of high velocity gradients that act as interfaces separating low-momentum flow regions near the pipe wall and high-momentum regions close to the pipe centre, where they eventually disappear. The thickness of the filaments was related to the level of drag reduction and increased with polymer concentration. They also reported that at a fixed polymer concentration, the thickness of the buffer layer increased with increasing polymer molecular weight, which consequently increased drag reduction. Edomwonyi-Otu et al. (2015) studied drag reduction in turbulent flows in a horizontal $14 \mathrm{~mm}$ ID pipe using Magnafloc 1011 (hydrolysed copolymer of polyacrylamide and sodium acrylate, HPAM) in water. PIV measurements showed that the velocity profile approached a parabolic shape when polymer was added, suggesting a laminarization of the flow, while the Reynolds, radial and axial stress tensors were reduced. With increasing polymer concentration and Reynolds number, the logarithmic velocity profile approached that of the maximum drag reduction asymptote (MDRA) (Edomwonyi-Otu et al. 2015; Virk, 1975).

The applications of PIV to oil-water flows are limited (Chinaud et al., 2017; Kumara et al., 2010a, 2010b, 2009; Morgan et al., 2017, 2013, 2012; Voulgaropoulos and Angeli (2017) and none has been reported when drag reducing polymers are present. Kumara et al. (2010a) carried out measurements in a $15 \mathrm{~m}$ long, $56 \mathrm{~mm}$ ID stainless steel pipe, at $0^{\circ}$ and $5^{\circ}$ pipe inclinations, using water and Exxsol D60 oil (density $790 \mathrm{~kg} / \mathrm{m}^{3}$ and viscosity $1.64 \mathrm{mPa}$ s) and found good agreement between LDA and PIV measurements. Mean velocities and turbulent intensity profiles were found to depend on pipe inclination. Kumara et al. (2010b) reported that while the presence of interfacial waves enhanced turbulence fluctuations, a damping effect of the Reynolds stress was observed near the interface due to density stratification. They concluded that the high axial velocity gradients in the near-wall region resulted in high values of the stress tensors in that region. Except for the slight distortions close the interface, the reported profiles were similar to those obtained for single phase flows. Morgan et al. $(2017,2013,2012)$ studied the flow of a water/glycerol solution (density $1205 \mathrm{~kg} / \mathrm{m}^{3}$ and viscosity $47 \mathrm{mPa}$ ) with Exxsol D80 oil (density $796 \mathrm{~kg} / \mathrm{m}^{3}$ and viscosity $2.3 \mathrm{mPa}$ ) in a $25.4 \mathrm{mmID}$ stainless steel pipe using PLIF, PTV and PIV techniques and obtained data on flow patterns, phase distribution, velocity profiles, interface level and droplet size distribution. The velocity profiles showed that the flow of the heavier and more viscous aqueous solution was always laminar while, depending on flowrates, the oil phase was either laminar or turbulent. Their experimental measurements of in- 
situ phase fractions and interface levels were well predicted by the two-fluid model. Chinaud et al. (2017) used PIV to study the effect of vortices shed from a cylinder on interfacial waves in oil-water separated flows. Combining PIV and LIF techniques, Voulgaropoulos and Angeli (2017) studied the development of oil-water dispersed flows in horizontal pipes and the changes in velocity fields and drop size distribution.

There are no current studies on the effect of drag reducing polymers on the turbulent properties of oil-water flows. This is despite the significant drag reduction found in these systems and the interesting changes in flow patterns when polymers are added in the flow. In this paper, the effects on the velocity profiles and turbulence properties are studied when the drag reducing polymer HPAM is added in the water layer of stratified oil-water flows. The resulrs are compared with those obtained when two different molecular weight PEO polymers are used.

\section{MATERIALS AND METHODS}

Drag reduction in horizontal oil-water flows was studied in a $4 \mathrm{~m}$ long, $14 \mathrm{~mm}$ ID acrylic pipe using tap water and a middle distillate oil, Exxsol D140, as test fluids (fluid properties are shown in Table 1). A schematic of the experimental flow facility can be seen in Fig.1.

\section{Table 1 Properties of test fluids}

\begin{tabular}{|l|l|l|}
\hline Properties & Oil & Water \\
\hline Density, $\mathrm{kg} / \mathrm{m}^{3}$ & 828 & 1000 \\
\hline Viscosity, $\mathrm{mPas}$ & $5.5 @ 20{ }^{\circ} \mathrm{C}$ & $1.0 @ 20^{\circ} \mathrm{C}$ \\
\hline Interfacial tension, $\mathrm{mN} / \mathrm{m}$ & $39.6 @ 20^{\circ} \mathrm{C}$ \\
\hline
\end{tabular}

The two fluids are stored in separate tanks (160 litres each) and are introduced into the test section through centrifugal pumps. The flow rates of the water and oil phases are controlled by two variable area flowmeters each with maximum flowrate $7.5 \mathrm{l} / \mathrm{min}$ and an uncertainty of 0.013 $1 / \mathrm{min}( \pm 0.20 \%)$. A $35 \mathrm{l} / \mathrm{min}$ flowmeter with an uncertainty of $0.06 \mathrm{l} / \mathrm{min}( \pm 0.20 \%)$ was used for flowrates higher than $8 \mathrm{l} / \mathrm{min}$ during single phase water flow measurements. The fluids join at the test section inlet through a Y-junction that minimises mixing. After the test section, the two fluids flow into a 250 litres separator tank from where the oil is returned to its storage tank after separation. In this work the water phase was not recycled but fresh water with new polymer solution was used in each run to avoid degradation effects in the pump (for details of the experimental set up see Edomwonyi-Otu et al., 2015). The separation is based on gravity and the 
separator is designed with partitions inside to enhance its efficiency. It was found that the size of the separator is sufficient to fully separate the two phases at the flowrates used.

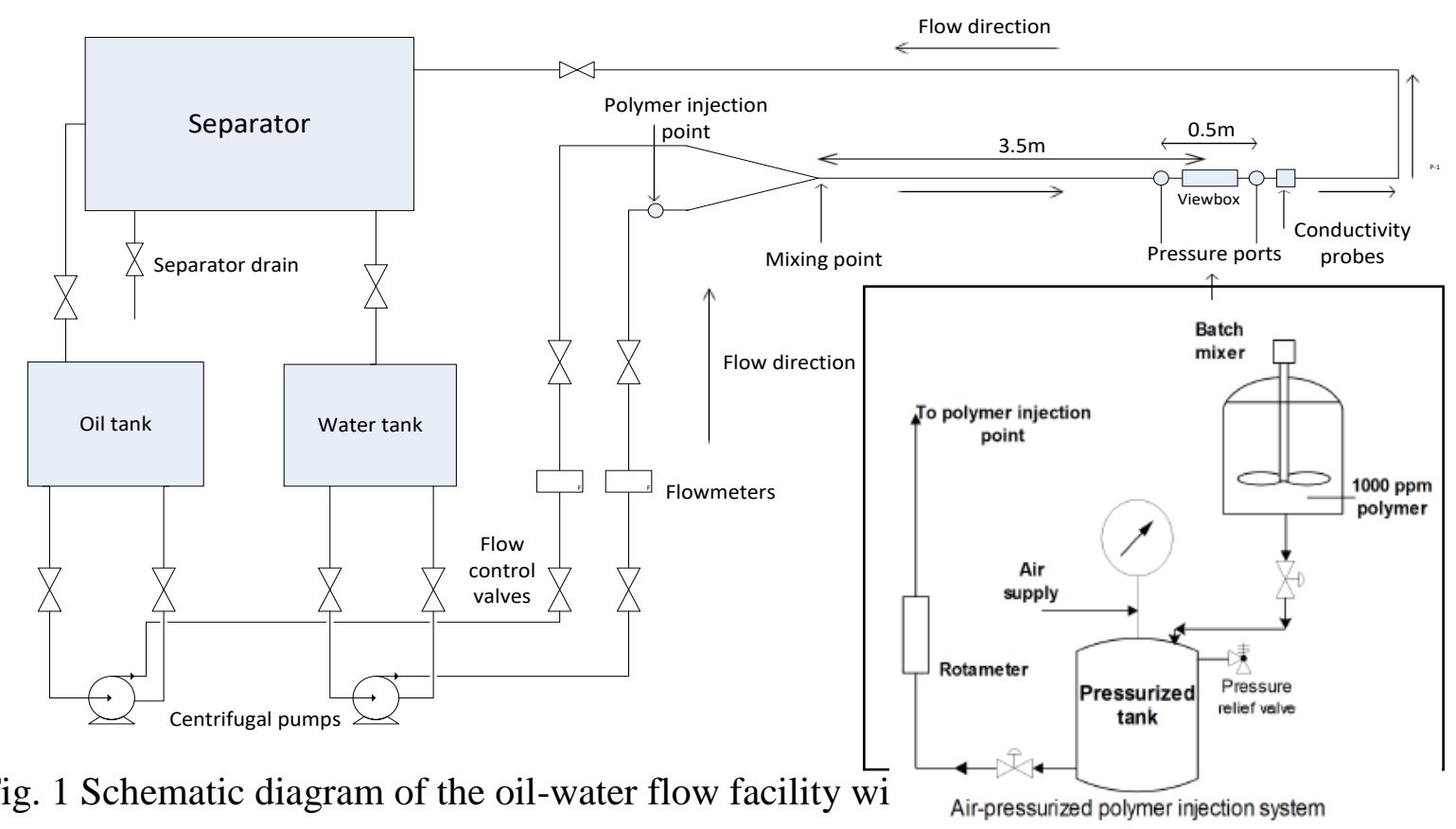

The oil-water flow conditions studied were within the stratified flow region with very small interfacial waves (Edomwonyi-Otu and Angeli, 2015) which can pose problems in the PIV measurements close to the interface. These conditions include superficial oil velocities (Uso) of $0.110 \mathrm{~m} / \mathrm{s}, 0.150 \mathrm{~m} / \mathrm{s}, 0.195 \mathrm{~m} / \mathrm{s}$, and $0.246 \mathrm{~m} / \mathrm{s}$, and superficial water velocities (Usw) from $0.166 \mathrm{~m} / \mathrm{s}$ to $0.280 \mathrm{~m} / \mathrm{s}$. For the drag reduction experiments, $20 \mathrm{ppm}$ of Magnafloc 1011 (a copolymer of polyacrylamide and sodium acrylate; HPAM, mol wt $=10 \times 10^{6} \mathrm{~g} / \mathrm{mol}$ ) was added in the water phase only. The $20 \mathrm{ppm}$ concentration was chosen since it gives drag reduction close to the maximum for these flowrates (Edomwonyi-Otu et al., 2015; Al-Wahaibi et al., 2007) . A few cases were also run with Polyethylene Oxide (PEO) as drag reducing agent, at two different molecular weights, $5 \times 10^{6} \mathrm{~g} / \mathrm{mol}$ (5MPEO) and $8 \times 10^{6} \mathrm{~g} / \mathrm{mol}$ (8MPEO) and the same $20 \mathrm{ppm}$ concentration in the water phase. All polymers used are highly soluble in water. A master solution of $1000 \mathrm{ppm}$ polymer was initially prepared by slowly dissolving $10 \mathrm{~g}$ of the polymer powder into 10 litres of water which was stirred with a 3-bladed mechanical stirrer (Heildolph, D-91126) for about four hours. The solution was then left overnight to allow for proper hydration of the polymer molecules and escape of trapped gas bubbles.

The master solution was injected into the water phase in the test section using an air-pressurized system (see inset in Fig. 1). Air was supplied into a high pressure vessel containing the polymer master solution at sufficient pressure to push the solution into the test section. The flowrate of the polymer into the test section was regulated with a flowmeter. The polymer injection point is 
a single hole, $1.50 \mathrm{~mm}$ diameter, located at the bottom of the water inlet pipe, $0.50 \mathrm{~m}$ upstream the mixing point of the two fluids. The water phase then flows through an acrylic mesh in the water inlet of the Y-junction which ensures further mixing. Pressure drop was measured with a differential pressure transducer (ABB 266MST $0.04 \%$ base accuracy) connected to two pressure ports, $0.50 \mathrm{~m}$ apart, located at $3.25 \mathrm{~m}$ and $3.75 \mathrm{~m}$ respectively from the point where the two fluids join. Preliminary tests showed that the pressure drop was the same both at midway downstream (between $1.75 \mathrm{~m}$ and $2.25 \mathrm{~m}$ ) and at the measuring point (between $3.25 \mathrm{~m}$ and 3.75 $\mathrm{m})$. For each set of conditions pressure drop was measured three times giving a standard deviation of less than $1.0 \%$. The average interface position was measured with conductance probes (Edomwonyi-Otu and Angeli, 2015; Barral and Angeli, 2013).

The PIV measurements were carried out at $3.50 \mathrm{~m}$ (250D) from the inlet. An acrylic box filled with glycerol was placed around the pipe to reduce optical distortions. A high power (400 mJ), double-pulsed, Nd:YAG laser (Litron: S65-15PIV) was used to generate green light (532 nm) at a frequency of $7.25 \mathrm{~Hz}$. A laser arm, which contains a set of convex and concave lenses, was used to guide the light and generate a sheet with thickness of about $1.0 \mathrm{~mm}$ that illuminated the pipe exactly in the middle along the flow direction (see Fig. 2).

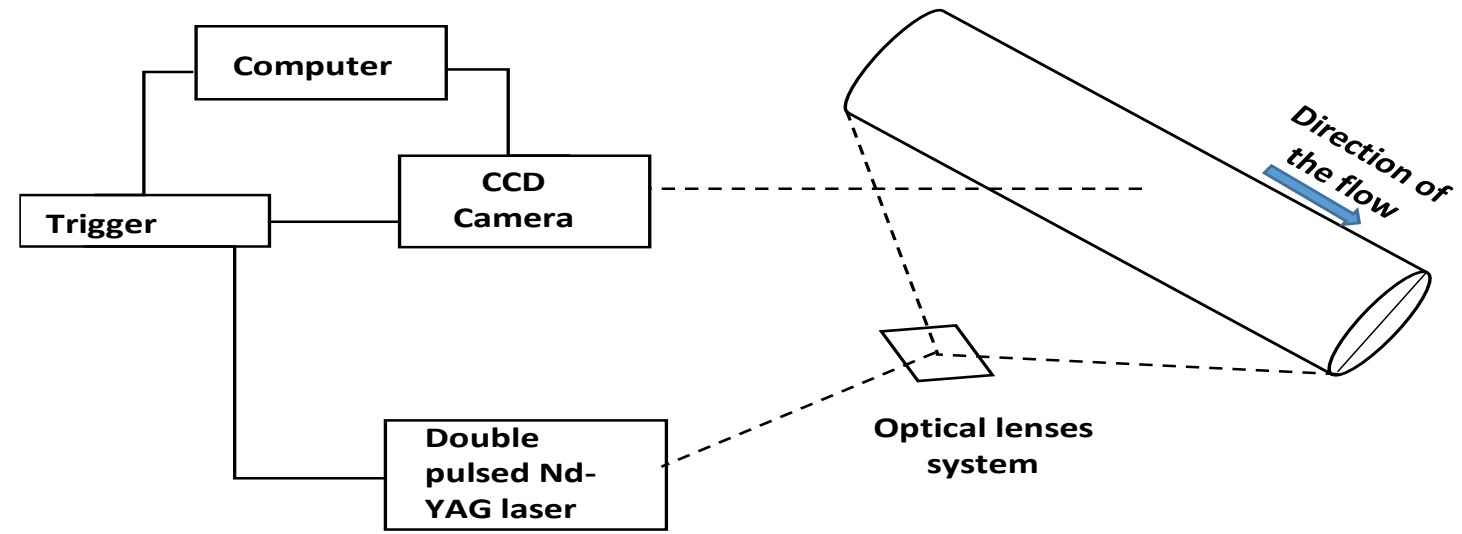

Fig. 2 Schematic of the PIV setup

The time delay between the laser pulses depended on the flowrates and varied between $500 \mu$ s to 100ms. A high-resolution 4MP (1024 x 1024) CCD frame straddling PowerView PIV camera (TSI) was used to acquire images at $8 \mathrm{fps}$ in front of the view box. The camera was equipped with a $60 \mathrm{~mm}$ Nikon lens, set at f/16 aperture. The laser pulses and the image acquisition were controlled by a synchroniser (TSI). The tracer particles needed in the PIV measurements were added in the water tank. Silver-coated glass particles (TSI, 10089-SLVR) with $12 \mu \mathrm{m}$ diameter and density of $1220 \mathrm{~kg} / \mathrm{m}^{3}$ were used. The particles Stokes number for the conditions studied varied between 0.00012 and 0.0014 , indicating that they faithfully follow the flow (Adrian and Westerweel, 2011). 
For each set of flowrates, the flow was allowed to stabilize for about 5 minutes before any measurements were taken. Over 400 image pairs were collected for each flow condition, which allowed the calculation of mean velocities and turbulence properties. The INSIGHT 3G software (TSI) was used for data acquisition and generation of the velocity vectors while the data analysis was done using a MatLab code developed in-house. Within INSIGHT 3G/4G, a background of the captured images was generated at minimum intensity which was subtracted from the images. A rectangular mask was then used to mark the area of interest. In these experiments, only the water phase was seeded and the mask isolated it from the oil phase. Each image pair was processed separately, and an ensemble average was calculated from the over 400 image pairs for each set of conditions. The images were divided into 32 by 32pixel interrogation windows with $50 \%$ overlap, which gave a spatial resolution of $0.21 \mathrm{~mm}$. The errors in the regions near the wall, interface and middle of the flow were about $5.56 \%, 10 \%$ and $0.5 \%$ respectively. Since the regions close to the wall and the interface constitute a small part of the water flow section, the average error was found to be about $1.6 \%$. A median filter was used to remove bad vectors and replace them with vectors interpolated from neighbouring ones. Using the ensemble average of the acquired images, the mean velocity components in the axial (U) and radial (V) directions of the flow were estimated as follows:

$$
\begin{aligned}
& \mathrm{U}=\frac{1}{\mathrm{~N}} \sum_{\mathrm{i}=1}^{\mathrm{N}} \mathrm{u}_{\mathrm{i}} \\
& \mathrm{V}=\frac{1}{\mathrm{~N}} \sum_{\mathrm{i}=1}^{\mathrm{N}} \mathrm{v}_{\mathrm{i}}
\end{aligned}
$$

Here, $\mathrm{u}_{\mathrm{i}}$ and $\mathrm{v}_{\mathrm{i}}$ are respectively the instantaneous velocity components in the axial and radial directions and $\mathrm{N}$ is the sample number. The stress tensors were calculated as follows:

$$
\begin{aligned}
& \overline{\mathrm{u}^{\prime 2}}=\frac{1}{\mathrm{~N}} \sum_{\mathrm{i}=1}^{\mathrm{N}}\left(\mathrm{u}_{\mathrm{i}}-\mathrm{U}\right)^{2} \\
& \overline{\mathrm{v}^{\prime 2}}=\frac{1}{\mathrm{~N}} \sum_{\mathrm{i}=1}^{\mathrm{N}}\left(\mathrm{v}_{\mathrm{i}}-\mathrm{V}\right)^{2} \\
& \overline{\mathrm{u}^{\prime}-\mathrm{v}^{\prime}}=\frac{1}{\mathrm{~N}} \sum_{\mathrm{i}=1}^{\mathrm{N}}\left(\mathrm{u}_{\mathrm{i}}-\mathrm{U}\right)\left(\mathrm{v}_{\mathrm{i}}-\mathrm{V}\right)
\end{aligned}
$$

where $\overline{\mathrm{u}^{\prime 2}}, \overline{\mathrm{v}^{\prime 2}}$, and $\overline{\mathrm{u}^{\prime}-\mathrm{v}^{\prime}}$ are respectively the time-averaged axial, radial and Reynolds stress (or cross moment) tensors, while $\mathrm{u}^{1}$ and $\mathrm{v}^{1}$ represent the fluctuating velocity components in the axial and radial directions respectively. 
The velocity profiles obtained from the PIV measurements for single phase water flows where validated against theoretical profiles. The experimental data were compared against the log-law profile for the regions near the wall and the power law profile for the rest of the flow, respectively. It was found that the experimental profiles deviated $4.04 \%$ in the regions close to the wall and $1 \%$ in the rest of the pipe cross-section resulting in an average error of $1.51 \%$.

\section{RESULTS AND DISCUSSION}

\subsection{Effect of Polymer on Pressure Drop and Average In-situ Phase Velocities}

The experimental conditions used in this work are shown in Table 2, together with the average in-situ phase velocities, Uo and Uw, and the in-situ Reynolds numbers, Reo and Rew, for the oil and the water phases respectively. The phase Reynolds numbers were calculated from Equations 7 and 8:

$\operatorname{Re}_{w}=\frac{\rho_{w} U_{w} D_{w}}{\mu_{w}}$

where $R e_{w}, \rho_{w}, \mu_{w}, U_{w}, D_{w}$ is Reynolds number, density, viscosity, in-situ velocity and hydraulic diameter of the water phase respectively in the pipe. $D_{w}$ is given by:

$D_{w}=\frac{4 \times A_{w}}{S_{i}+S_{w}}$

where $A_{w}$ is the wall wetted area of the water phase, $S_{w}$ is the wall wetted perimeter of the water phase, and $S_{i}$ is the length of the oil-water interface. See Edomwonyi-Otu and Angeli, (2015) for more details.

The in-situ velocities were calculated from the interface heights measured with the conductance probes (for details see Edomwonyi-Otu and Angeli, 2015). As can be seen, the oil flow is laminar while the water flow is in the transitional/turbulent region. The velocity ratio, S, (ratio of average in situ oil to water velocities) is always less than 1, irrespective of the superficial oil velocity, indicating that the oil phase flows slower than water. When the polymer is added in water, the interface heights is decreased, indicating that water has higher average velocity than in the cases without polymer, and the velocity ratio also decreases. For example, in the flow without polymer of Uso $=0.245 \mathrm{~m} / \mathrm{s}$ and Usw $=0.22 \mathrm{~m} / \mathrm{s}$, the average water velocity calculated from the interface height is $\mathrm{Uw}=0.498$ (see Table 2); using the velocity profile an average water velocity of $0.49 \mathrm{~m} / \mathrm{s}$ was found. With polymer addition, the average water velocity increased to $0.521 \mathrm{~m} / \mathrm{s}$ (and $0.52 \mathrm{~m} / \mathrm{s}$ from the profile, Figure 4c). This can be explained as a result of the 
reduced frictional resistance in the water layer (drag reduction) that lead to increased velocity (Al-Yaari et al., 2012). For a constant water flowrate an increase in velocity would decrease the in-situ water holdup and the interface height. For example, at Uso $=0.195 \mathrm{~m} / \mathrm{s}, 0.245 \mathrm{~m} / \mathrm{s}$ and Usw $=0.28 \mathrm{~m} / \mathrm{s}$, the interface height reduced by about $15 \%$, while it reduced by about $10 \%$ for Uso $=0.245 \mathrm{~m} / \mathrm{s}$ and Usw $=0.22 \mathrm{~m} / \mathrm{s}$ after the addition of polymer to the water phase. This differs from the findings by Abubakar et al. (2015) who observed that the addition of watersoluble polymer to oil-water flows resulted in an increase in the water hold up and the corresponding velocity ratio, particularly at low mixture velocities within the stratified flow pattern. In contrast to the current work where the oil flow is laminar, in their case the oil was in the turbulent regime, which may have affected the momentum balances of the phases and the final interface height.

Table 2 Experimental conditions and in-situ parameters for the stratified oil-water flows studied before polymer addition.

\begin{tabular}{|l|l|l|l|l|l|l|}
\hline Uso $(\mathbf{m} / \mathbf{s})$ & Usw $(\mathbf{m} / \mathbf{s})$ & Uo $(\mathbf{m} / \mathbf{s})$ & Uw $(\mathbf{m} / \mathbf{s})$ & Reo & Rew & S $=\frac{\text { Uo }}{\mathrm{Uw}}$ \\
\hline $\mathbf{0 . 1 1 0}$ & $\mathbf{0 . 1 6 6}$ & 0.221 & 0.331 & 465 & 2837 & 0.668 \\
\hline & $\mathbf{0 . 2 2 0}$ & 0.232 & 0.422 & 476 & 3739 & 0.550 \\
\hline $\mathbf{0 . 1 5 0}$ & $\mathbf{0 . 1 6 6}$ & 0.267 & 0.379 & 595 & 2957 & 0.704 \\
\hline & $\mathbf{0 . 2 2 0}$ & 0.293 & 0.456 & 624 & 3828 & 0.643 \\
\hline & $\mathbf{0 . 2 8 0}$ & 0.317 & 0.531 & 650 & 4713 & 0.597 \\
\hline $\mathbf{0 . 1 9 5}$ & $\mathbf{0 . 1 6 6}$ & 0.335 & 0.398 & 759 & 3002 & 0.842 \\
\hline & $\mathbf{0 . 2 2 0}$ & 0.352 & 0.497 & 780 & 3933 & 0.708 \\
\hline & $\mathbf{0 . 2 8 0}$ & 0.387 & 0.564 & 818 & 4801 & 0.686 \\
\hline $\mathbf{0 . 2 4 5}$ & $\mathbf{0 . 1 6 6}$ & 0.396 & 0.436 & 921 & 3090. & 0.908 \\
\hline & $\mathbf{0 . 2 2 0}$ & 0.442 & 0.498 & 979 & 3935 & 0.888 \\
\hline & $\mathbf{0 . 2 8 0}$ & 0.380 & 0.790 & 897 & 5339 & 0.481 \\
\hline
\end{tabular}

The reduction in pressure drop with the addition of polymer in the water phase can be seen in Fig. 3 for the different oil and water superficial velocities.

It can be observed from Fig. 3 that drag reduction increased with increasing water velocity for the flow without oil. Interestingly, drag reduction decreased by almost a third with the addition of oil at Uso $=0.11 \mathrm{~m} / \mathrm{s}$. The decrease in drag reduction from the single phase to the two-phase flow is probably because with the addition of oil less of the water phase is in contact with the pipe wall and any effect of the polymer on frictional drag is limited to the water phase.

The maximum drag reduction observed was about $55 \%$ for the oil-water flows. Drag reduction increases with increasing superficial water velocity for all superficial oil velocities. At each superficial oil velocity, as the superficial water velocity increases, the average in-situ water 
velocity, Uw, and Rew also increase and enhance turbulence which leads to higher drag reduction (Abubakar et al., 2014a; Al-Sarkhi, 2010; Manfield et al., 1999). With increasing Uso and constant Usw, drag reduction increases until Uso $=0.195 \mathrm{~m} / \mathrm{s}$. For each Usw, with increasing Uso, the Rew increases because the water velocity increases; this increase happens even though locally the amount of water decreases with increasing Uso.

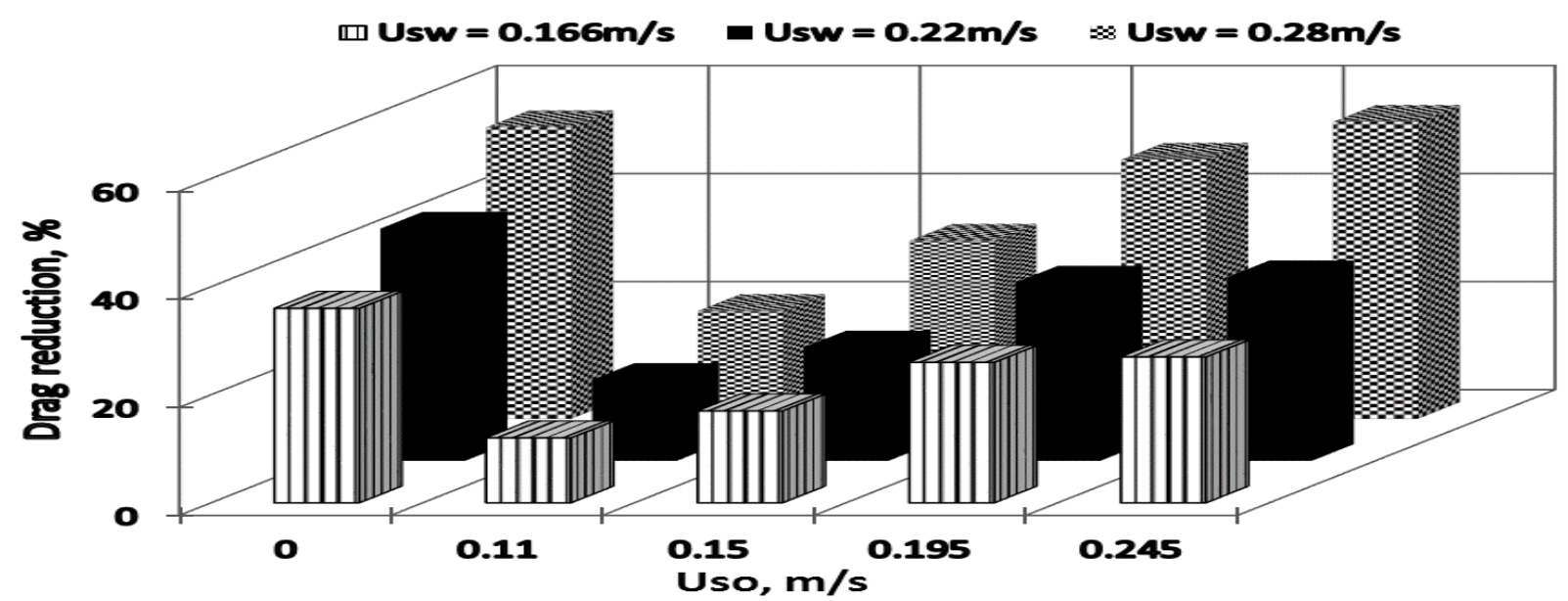

Fig. 3 Drag reduction (\%) in the single phase water and in the oil-water flows for different superficial water (Usw) and oil (Uso) velocities

For the highest water superficial velocity used (Usw $=0.28 \mathrm{~m} / \mathrm{s}$ ) the drag reduction continues to increase at Uso $=0.245 \mathrm{~m} / \mathrm{s}$. At the two low water velocities, though, (Usw $=0.166 \mathrm{~m} / \mathrm{s}$ and 0.22 $\mathrm{m} / \mathrm{s}$ ) there is a slight decrease (larger than the experimental error) in drag reduction when Uso changes from $0.195 \mathrm{~m} / \mathrm{s}$ to $0.245 \mathrm{~m} / \mathrm{s}$. In both these water velocities, the in-situ Rew increases with oil velocity. It is possible that as the oil flowrate increases and oil occupies a larger part of the pipe cross section, its contribution to the two-phase pressure drop is more important to that of the water phase, particularly at low water flowrates (see Table 2). Some investigators (Abubakar et al., 2015; Al-Wahaibi et al., 2012; Al-Yaari et al., 2012) also found decreased drag reduction with increasing input oil fraction. Abubakar et al. (2015) reported that the addition of water-soluble polymer to oil-water flows can even result in negative drag reduction at very high input oil fractions. They observed maximum drag reduction of $64 \%$ at the highest mixture velocity and lowest input oil fraction.

\subsection{Influence of Polymer on Mean Axial Velocity}

In the figures that follow, the 0 in the $y$-axis represents the middle of the $14 \mathrm{~mm}$ pipe with $7 \mathrm{~mm}$ representing the lower pipe wall. The top symbols in Figures 4 - 7 indicate the average location of the interface. The mean axial velocity profiles in the water phase calculated from the PIV measurements both before and after the addition of polymer are shown in Fig. 4. Three oil 
superficial velocities of $0.110 \mathrm{~m} / \mathrm{s}, 0.195 \mathrm{~m} / \mathrm{s}$ and $0.245 \mathrm{~m} / \mathrm{s}$ and water superficial velocities of $0.166 \mathrm{~m} / \mathrm{s}$ and $0.220 \mathrm{~m} / \mathrm{s}$ are considered here.

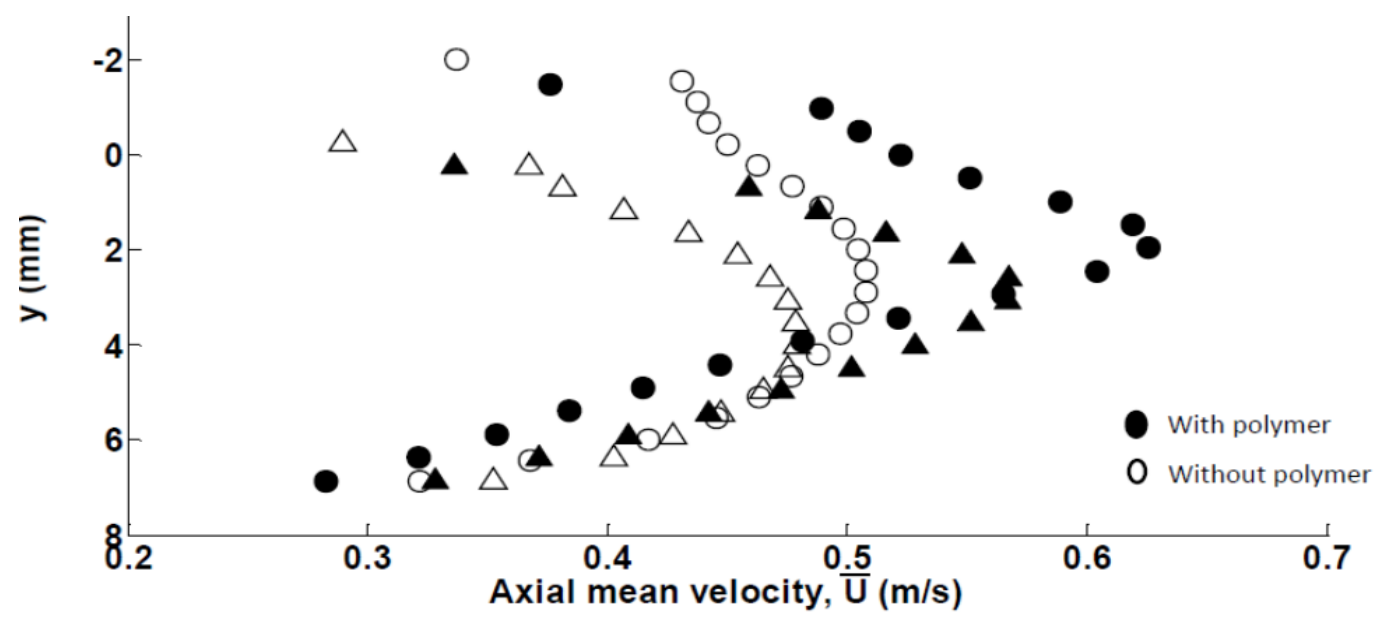

a) Uso $=0.110 \mathrm{~m} / \mathrm{s} ;$ Usw $=0.166 \mathrm{~m} / \mathrm{s}$ (triangles) and Usw $=0.220 \mathrm{~m} / \mathrm{s}$ (circles)

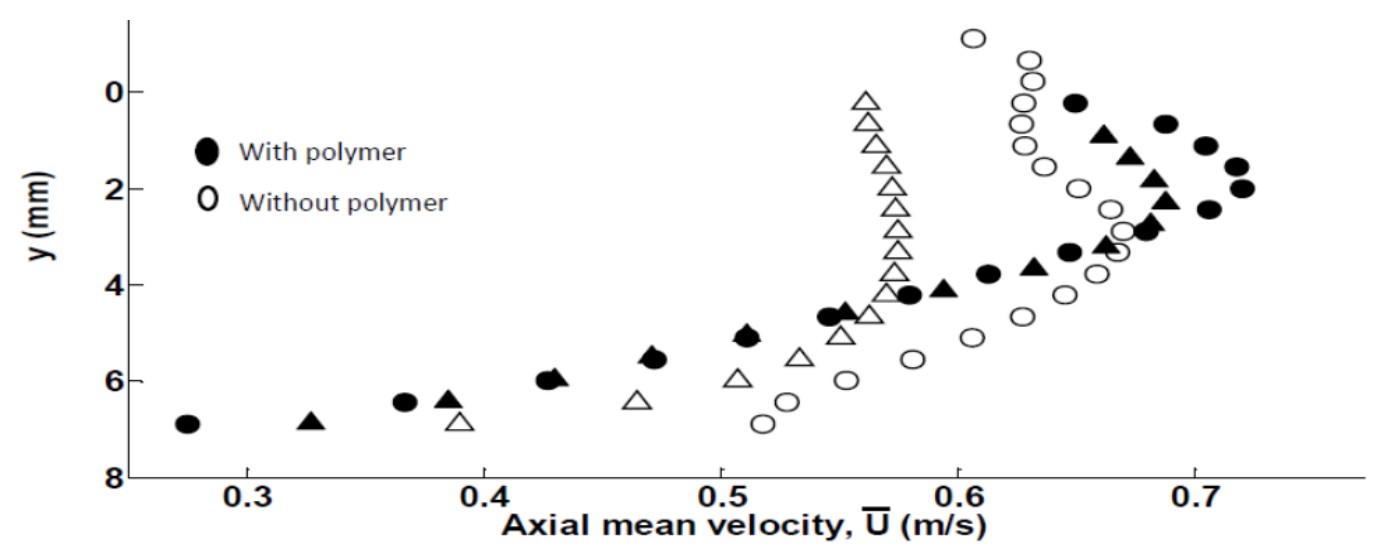

b) Uso $=0.195 \mathrm{~m} / \mathrm{s}$, Usw $=0.166 \mathrm{~m} / \mathrm{s}$ (triangles) and Usw $=0.220 \mathrm{~m} / \mathrm{s}$ (circles)

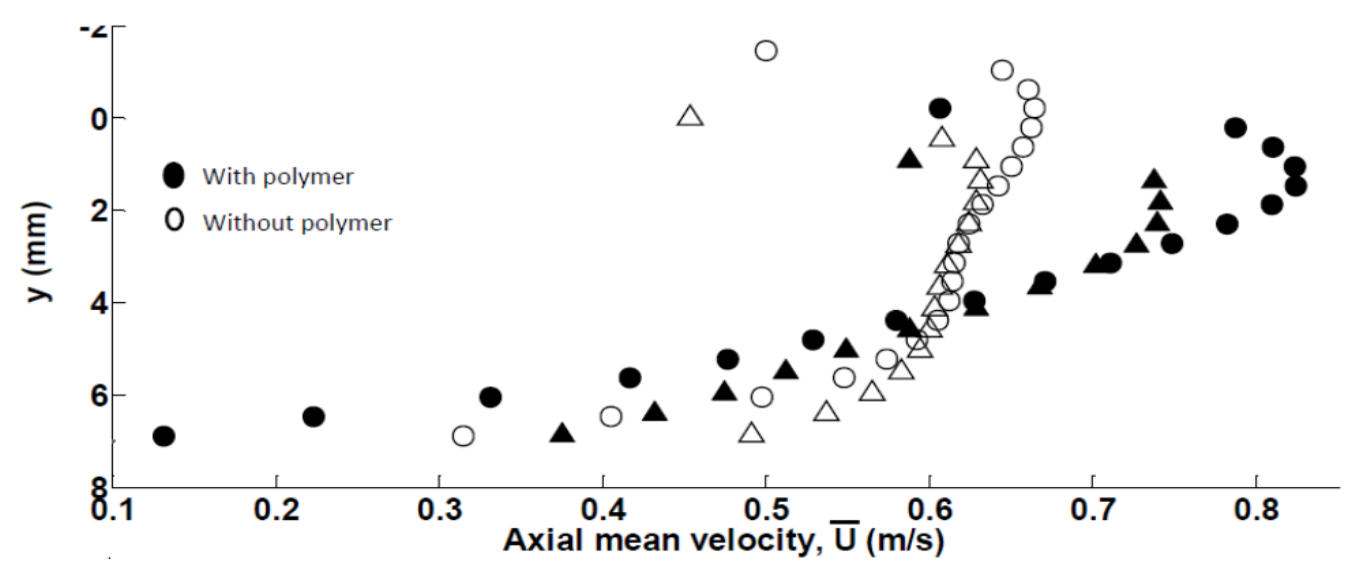

c) Uso $=0.245 \mathrm{~m} / \mathrm{s} ;$ Usw $=0.166 \mathrm{~m} / \mathrm{s}$ (triangle) and Usw $=0.220 \mathrm{~m} / \mathrm{s}($ circles $)$

Fig. 4 Mean axial velocity profiles in the water phase.

In the flow without polymer, the maximum of the axial velocity profiles increases with water velocity. From Table 2 and at Uso $=0.110 \mathrm{~m} / \mathrm{s}$, the average in-situ water velocities are in both 
cases higher than those of the oil $(\mathrm{Uo}=0.221 \mathrm{~m} / \mathrm{s}, \mathrm{Uw}=0.331 \mathrm{~m} / \mathrm{s} ;$ Uo $=0.232 \mathrm{~m} / \mathrm{s}$, Uw $=$ $0.422 \mathrm{~m} / \mathrm{s}$ ) and the peaks of the velocity profiles are away from the interface. At Uso $=0.195$ $\mathrm{m} / \mathrm{s}$, the superficial water velocities are in one case lower (Usw $=0.166 \mathrm{~m} / \mathrm{s}$ ) and in the other case higher $(\mathrm{Usw}=0.220 \mathrm{~m} / \mathrm{s})$ than the oil. The in-situ water velocities are in both cases higher than those of the oil (Uo $=0.335 \mathrm{~m} / \mathrm{s}, \mathrm{Uw}=0.398 \mathrm{~m} / \mathrm{s} ; \mathrm{Uo}=0.352 \mathrm{~m} / \mathrm{s}$, Uw $=0.497 \mathrm{~m} / \mathrm{s})$ but their difference has decreased compared to the first case and the maximum of the axial velocity profiles has shifted closer to the interface. At Uso $=0.245 \mathrm{~m} / \mathrm{s}$ even though the superficial oil velocity is higher than both the superficial water velocities, the in-situ oil velocity is again less than the water velocities $(\mathrm{Uo}=0.396 \mathrm{~m} / \mathrm{s}, \mathrm{Uw}=0.436$; Uo $=0.442 \mathrm{~m} / \mathrm{s}, \mathrm{Uw}=0.498 \mathrm{~m} / \mathrm{s}$ ). The maximum of the velocities is in this case close to the interface. The profiles are similar to those reported by Kumara et al. $(2010 \mathrm{a}, \mathrm{b})$ where the velocity of the water phase near the interface was found to increase with increasing oil superficial velocity at fixed water superficial velocity.

When polymer is added in water, the velocity profiles acquire a more parabolic shape while the maximum values increase. The profiles are closer to laminar flow although the actual Rew is higher than in the cases without polymer as previously reported (Edomwonyi-Otu et al., 2015). This change leads to a reduction in the axial velocity gradient (du/dy) in the region close to the wall and indicates an increase in the thickness of the boundary layer (Zadrazil et al., 2012; White and Mungal, 2008).

The average in-situ velocity in the water phase is higher than in the oil phase in all cases studied. Also, the peaks in the profiles are away from the interface, while they tend to approach the interface as the oil velocity increases. With the addition of polymer, the maximum axial water velocity increased by $12 \%$ to $30 \%$ compared to flows without polymer, for all flow conditions studied.

\subsection{Influence of Polymer on Stress Tensors}

\subsubsection{Axial stresses}

The axial stress tensors in the water phase calculated from Eq. 4 are plotted in Fig. 5 for the same conditions shown in Fig. 4 and for the flows without and with polymers. The term denotes axial momentum flux in the axial direction. For flows without polymer the tensors have their highest values in the regions close to the wall and the interface (Fig. 5). These are also regions of high shear rates in single and multiphase flows (Kumara et al., 2009; Schmitt, 2008).

The peak of the axial stress tensor in the lower wall region increases with increasing superficial and actual water velocity for a fixed superficial oil velocity. This indicates increase in turbulence production from these regions as a result of increased velocity gradient. The peak also generally 
increases for fixed superficial water velocity (but increasing in-situ water velocity) and increasing superficial oil velocity, apart from Uso $=0.245 \mathrm{~m} / \mathrm{s}$ and Usw $=0.166 \mathrm{~m} / \mathrm{s}$ (Uo = $0.396 \mathrm{~m} / \mathrm{s}, \mathrm{Uw}=0.436 \mathrm{~m} / \mathrm{s})$.

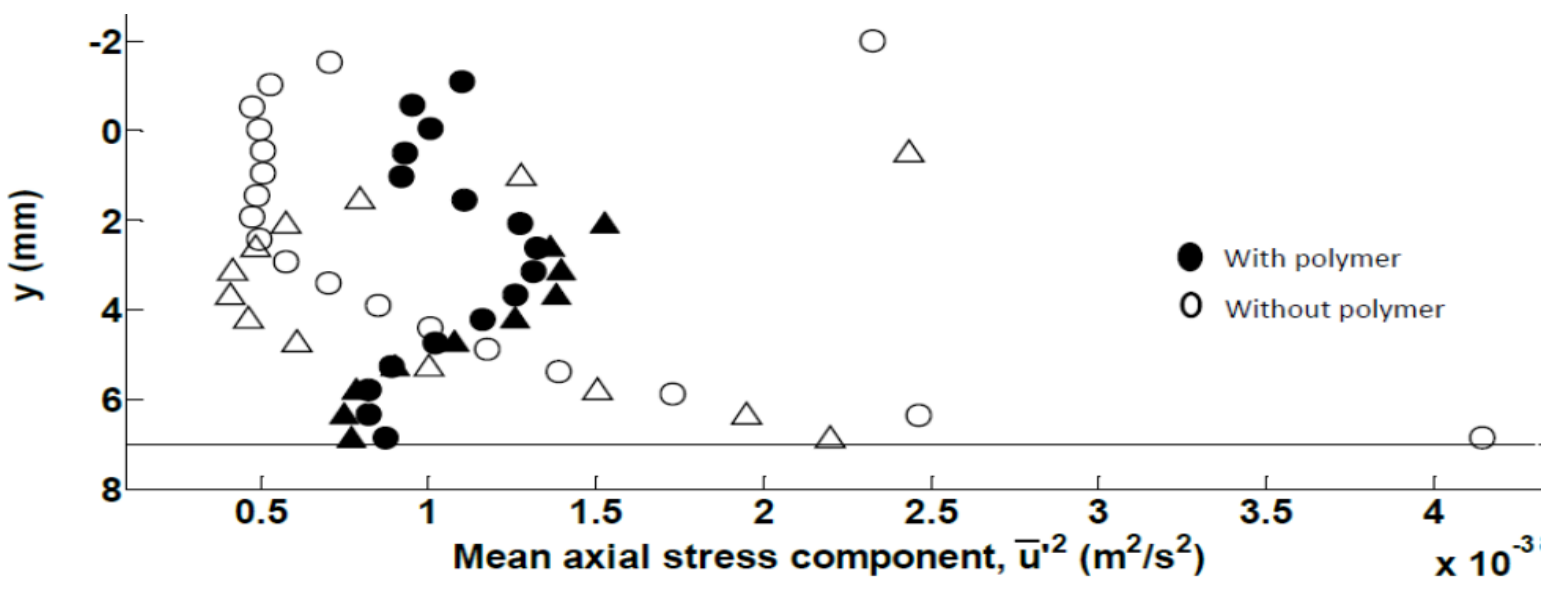

a) Uso $=0.110 \mathrm{~m} / \mathrm{s} ; \mathrm{Usw}=0.166 \mathrm{~m} / \mathrm{s}$ (triangle) and Usw $=0.220 \mathrm{~m} / \mathrm{s}$ (circles)

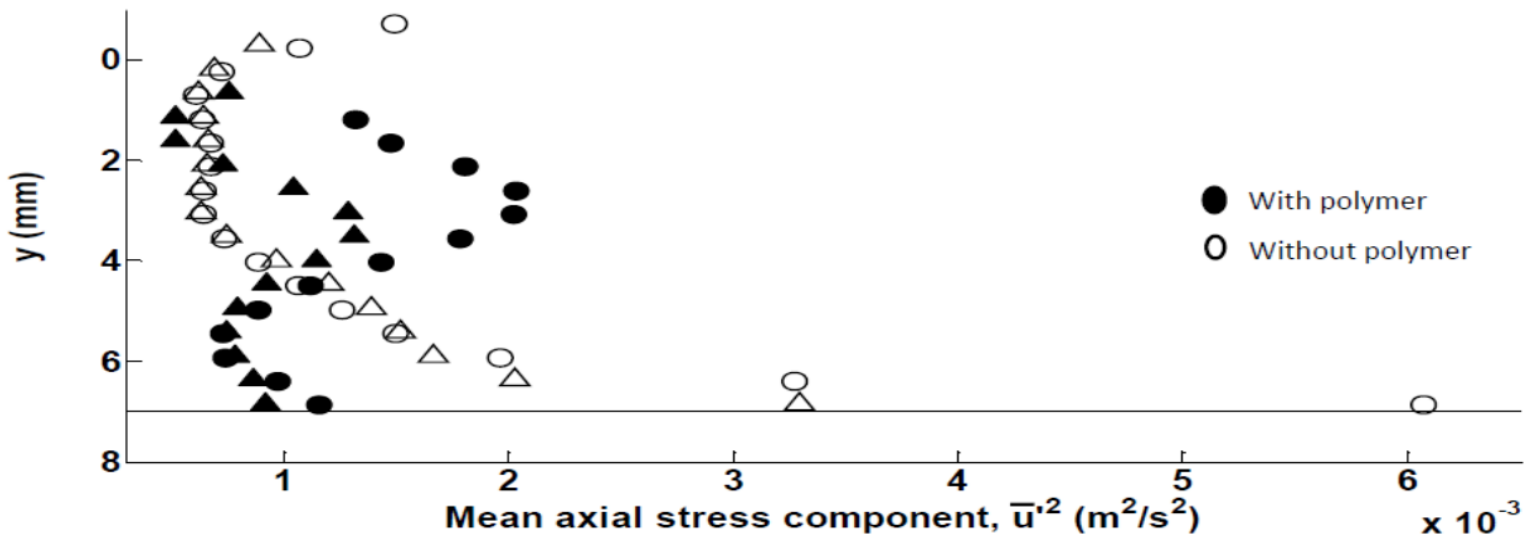

b) Uso $=0.195 \mathrm{~m} / \mathrm{s} ; \mathrm{Usw}=0.166 \mathrm{~m} / \mathrm{s}$ (triangle) and Usw $=0.220 \mathrm{~m} / \mathrm{s}$ (circles)

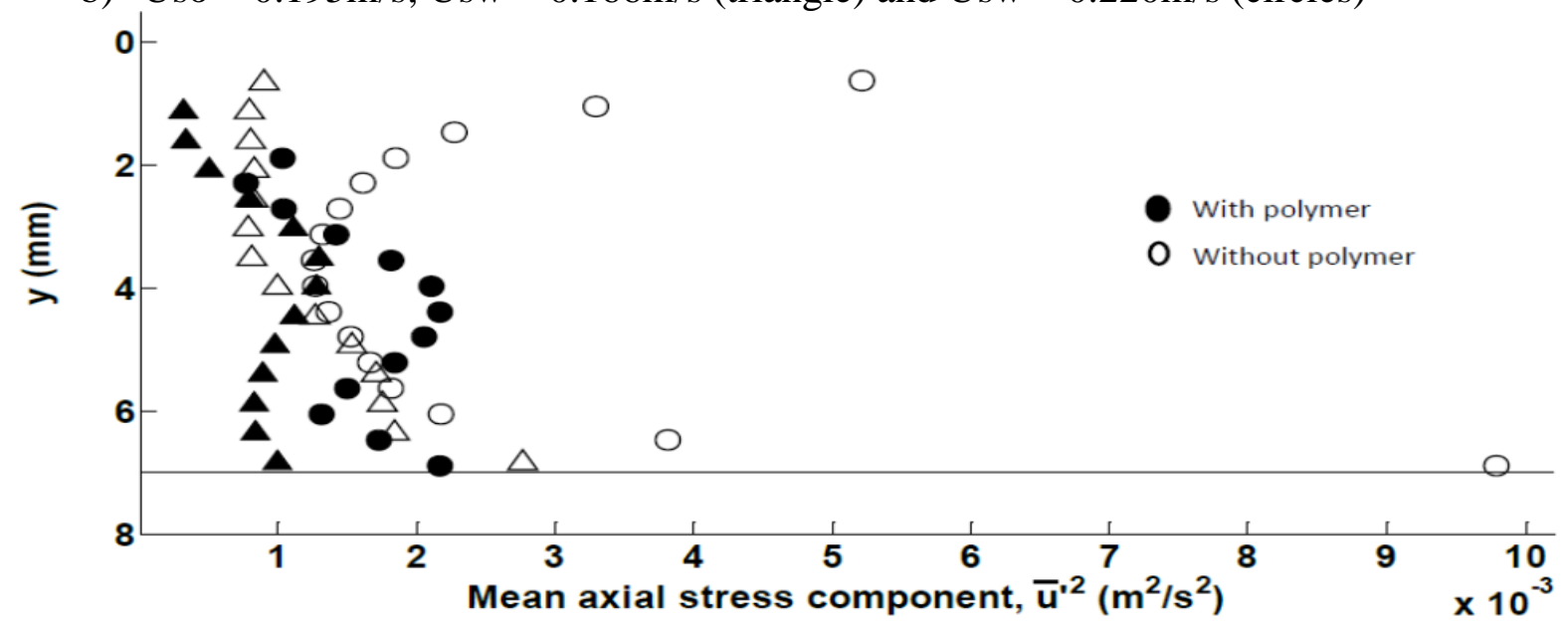

c) Uso $=0.245 \mathrm{~m} / \mathrm{s}$, where Usw $=0.166 \mathrm{~m} / \mathrm{s}$ (triangle) and Usw $=0.220 \mathrm{~m} / \mathrm{s}$ (circles)

Fig. 5 Mean axial stress tensor profiles in the water phase.

With the addition of polymer, there is a significant reduction of the axial stress tensors at the interface and the wall regions where the tensors were reduced by as much as $81 \%$ compared to 
the flows without polymer. This implies that the polymer is significantly active in the regions of high shear stresses. In the bulk water flow however, the axial stress tensors increased (see Fig. 5) which suggests an increase of the axial momentum flux in the direction of the flow. The increase is located in similar radial positions where the minimum values of the stress tensor were observed in the Newtonian flows. This is also similar to the location where the maximum values of the axial velocity appear (Schmitt, 2008; Zhang et al., 1998). This profile suggests an enhancement of the turbulent momentum flux in the direction of flow.

From studies in single phase water flows with drag reducing polymers, Zadrazil and Markides (2014) observed that as drag reduction increases, two flow regions exist within the pipe; a low momentum one near the wall and a high momentum one within the turbulent core. Wei and Willmarth, (1992), Warholic et al. (1999) and White et al. (2004) also reported an increase in the streamwise turbulence intensity after polymer addition with the peak further removed from the wall compared to Newtonian flows. They found, however, that the increase was restricted to drag reduction less than $64 \%$ and that at higher drag reduction (close to MDRA), the peak of the profile of the streamwise turbulence intensity reduces to values less than those in Newtonian flows. This decrease in the maximum value of the axial turbulent stresses in single phase flows was also found by Edomwonyi-Otu et al. (2015) for drag reductions of $65 \%$ and $74 \%$. The decrease of the axial turbulent stresses in the near wall region helps to reduce corrosion in pipes used for fluid transport (Kang et al., 1998; Sedahmed et al., 1999; Sellin et al., 1982; Zahran and Sedahmed, 1998).

\subsubsection{Radial stresses}

The radial stress tensors in the water phase, calculated from Eq. 5, are shown in Fig. 6 and for the flows without and with polymers. The term $\overline{\mathrm{v}^{\prime 2}}$ denotes radial momentum flux in the radial direction. These tensors are about an order of magnitude lower than the axial stress tensors. Unlike the axial stress tensors, the maximum value of the radial ones is in the bulk flow while in the region close to the pipe wall the values are low (Kumara et al., 2010a,b). The radial stresses are also large close to the interface (upper section of the profiles), because of the presence of small waves (Cheung and Street, 1988; Cohen and Hanratty, 1968).

As can be seen, at the low oil velocity, the radial stresses increase with superficial water velocity (Fig. 6a). With increasing water superficial velocity, the difference in the in-situ velocities of oil and water increases which leads to waves with higher amplitude at the interface. In addition, the water phase Rew increases, implying increased turbulence. Both these phenomena could explain the observed increase of the radial velocity fluctuations with superficial water velocity. At Uso $=$ 
$0.110 \mathrm{~m} / \mathrm{s}$ and Usw $=0.166 \mathrm{~m} / \mathrm{s}$, the relative in-situ velocity between the phases is $0.110 \mathrm{~m} / \mathrm{s}$ and the Rew $=2837$ while at Uso $=0.110 \mathrm{~m} / \mathrm{s}$ and Usw $=0.220 \mathrm{~m} / \mathrm{s}$, it is $0.190 \mathrm{~m} / \mathrm{s}$ and the Rew $=$ 3739. At higher oil superficial velocities, the stresses do not follow a unique trend; in these conditions the standard deviation in the radial fluctuations was about $10 \%$. The variations were particularly more pronounced in the near interface region for increasing Uso.

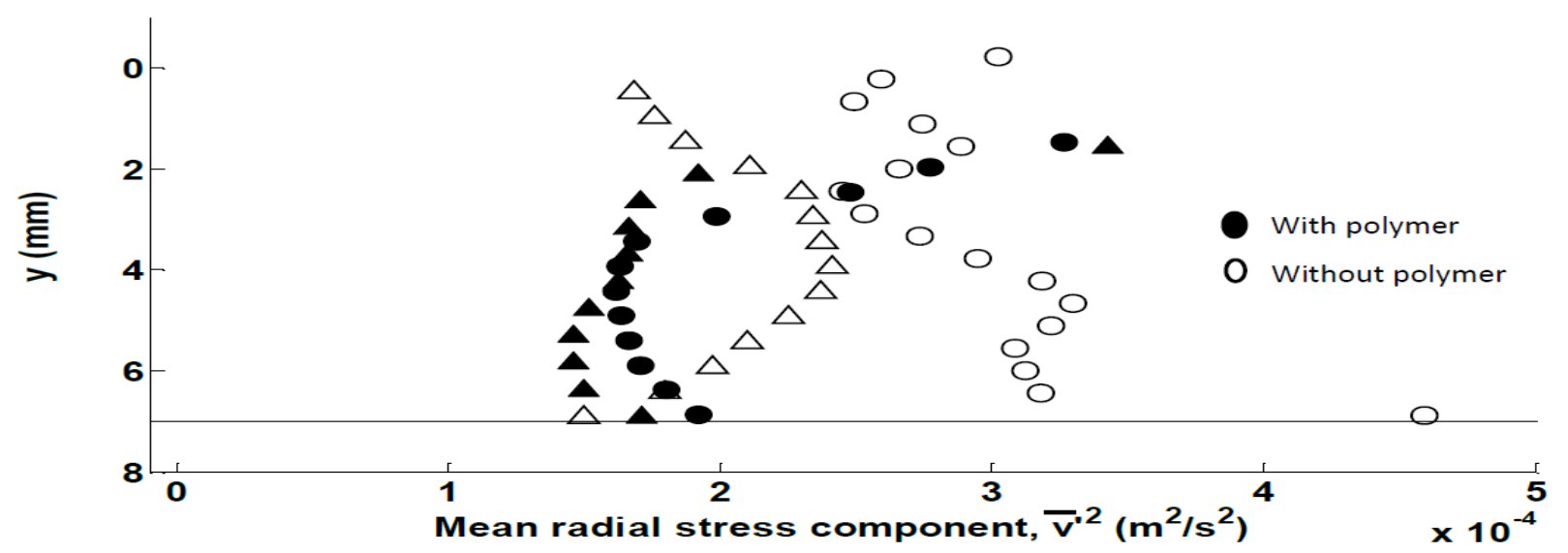

a) $\mathrm{Uso}=0.110 \mathrm{~m} / \mathrm{s} ; \mathrm{Usw}=0.166 \mathrm{~m} / \mathrm{s}$ (triangle) and Usw $=0.220 \mathrm{~m} / \mathrm{s}$ (circles)

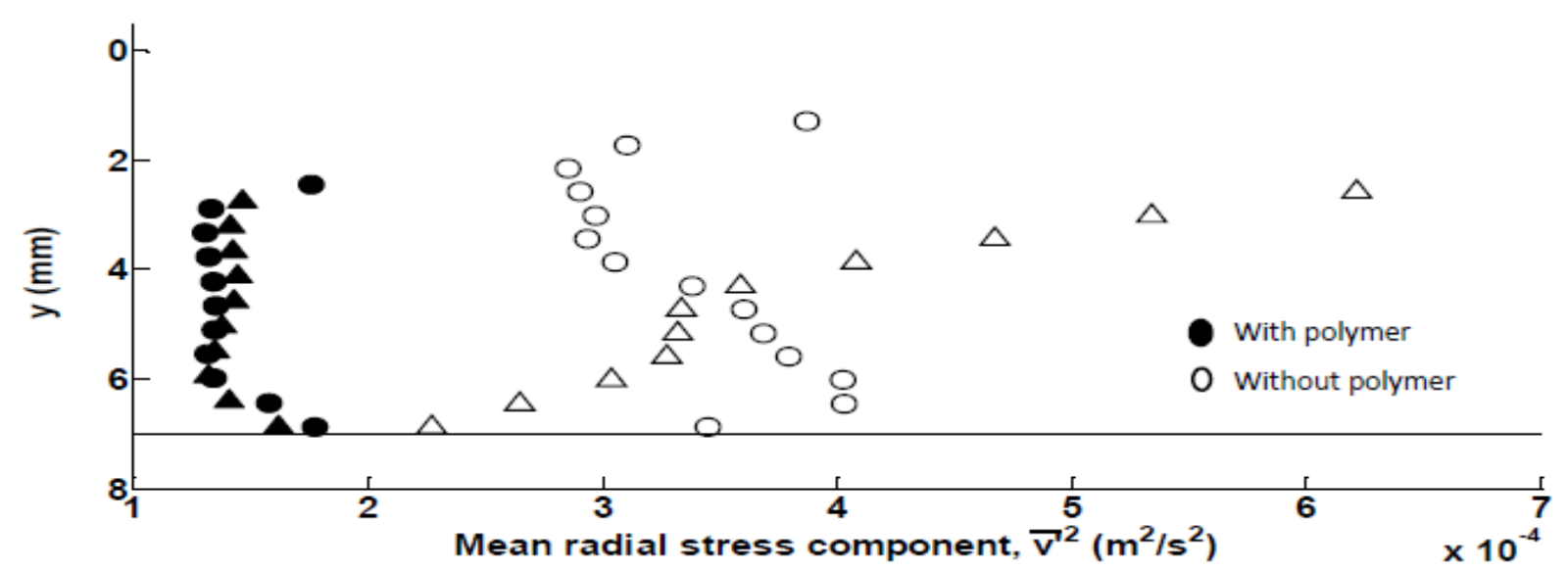

b) Uso $=0.195 \mathrm{~m} / \mathrm{s} ;$ Usw $=0.166 \mathrm{~m} / \mathrm{s}$ (triangle) and Usw $=0.220 \mathrm{~m} / \mathrm{s}($ circles $)$

Fig. 6 Mean radial stress tensor profiles in the water phase.

The addition of polymer led to a significant reduction of the radial stress tensor, mainly in the bulk flow, with values of $30-70 \%$ less than those in the flow without polymer. This reduction was more obvious for the two high superficial oil velocities used. The reduction suggests that the polymer reduces turbulent fluctuations and radial momentum transfer in the radial direction. The drag-reduced radial stress tensor profile for the superficial water velocities studied is similar at all Uso. 


\subsubsection{Reynolds stresses}

The Reynolds shear stress tensors $\overline{\mathrm{u}^{\prime} \mathrm{v}^{\prime}}$ in the water phase calculated from Eq. 6 are shown in Fig. 7 for the same conditions presented in Fig. 5 for flows without and with polymer. The term $\overline{u^{\prime} v^{\prime}}$ denotes the axial momentum flux in the radial direction. For the flows without polymer, the absolute values of the Reynolds stresses were found to increase with the superficial oil or water velocities. For the two lower oil superficial velocities (Uso $=0.110 \mathrm{~m} / \mathrm{s}$ and $0.195 \mathrm{~m} / \mathrm{s}$ ) with increasing distance from the wall the Reynolds shear stresses increase from negative to positive values and then decrease towards the interface, sometimes becoming negative again. For the higher Uso $(0.245 \mathrm{~m} / \mathrm{s})$ however, the Reynolds shear stresses increase with distance from the wall but remain negative. The sign of the term $\overline{u^{\prime} v^{\prime}}$ depends on the sign of the velocity gradient (Cowen, 2015) positive velocity gradients result in negative $\overline{u^{\prime} v^{\prime}}$ and vice versa. The signs of $\overline{u^{\prime} v^{\prime}}$ reflect the changes in the velocity gradients shown in Fig. 4. For the two lower oil superficial velocities (Figs. $4 \mathrm{~b}$ and $4 \mathrm{c}$ ), the velocity gradients are positive at the lower part of the pipe, have low values at the region of maximum velocity, while they become negative close to the interface. However, for Uso $=0.245 \mathrm{~m} / \mathrm{s}$, where the velocity gradients are positive throughout most of the water layer, $\overline{u^{\prime} v^{\prime}}$ remains negative for the whole water phase. It should be noted, that as was discussed in the Materials and Methods section, the points very close to the interface are subject to large errors and conclusions should be drawn with care. Similar (negative) Reynolds shear stresses were also found by Kumara et al. (2010b) in the water phase of upward inclined oil-water flows, when the oil velocity was higher compared to the water velocity. Also, Birvalski et al., (2014) reported a negative Reynolds stress profile because of the low water velocity compared to gas velocity in their horizontal air-water system.

When polymer was added to the flows, the absolute values of the Reynolds stresses reduced everywhere, and particularly in the near wall and near interface regions. The reduction of the maximum values in the near wall region was as much as $90 \%$ in some cases. The reduction increased with increasing water phase Reynolds numbers. 


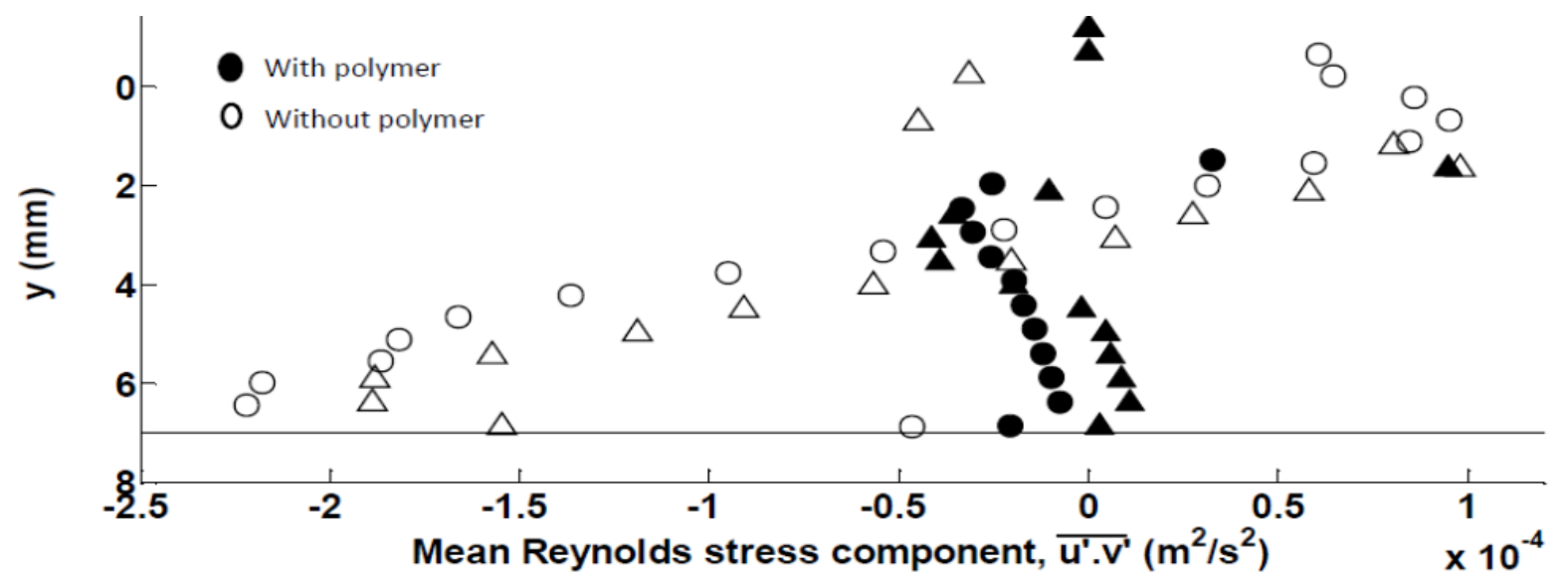

a) Uso $=0.110 \mathrm{~m} / \mathrm{s} ;$ Usw $=0.166 \mathrm{~m} / \mathrm{s}$ (triangle) and Usw $=0.220 \mathrm{~m} / \mathrm{s}$ (circles)

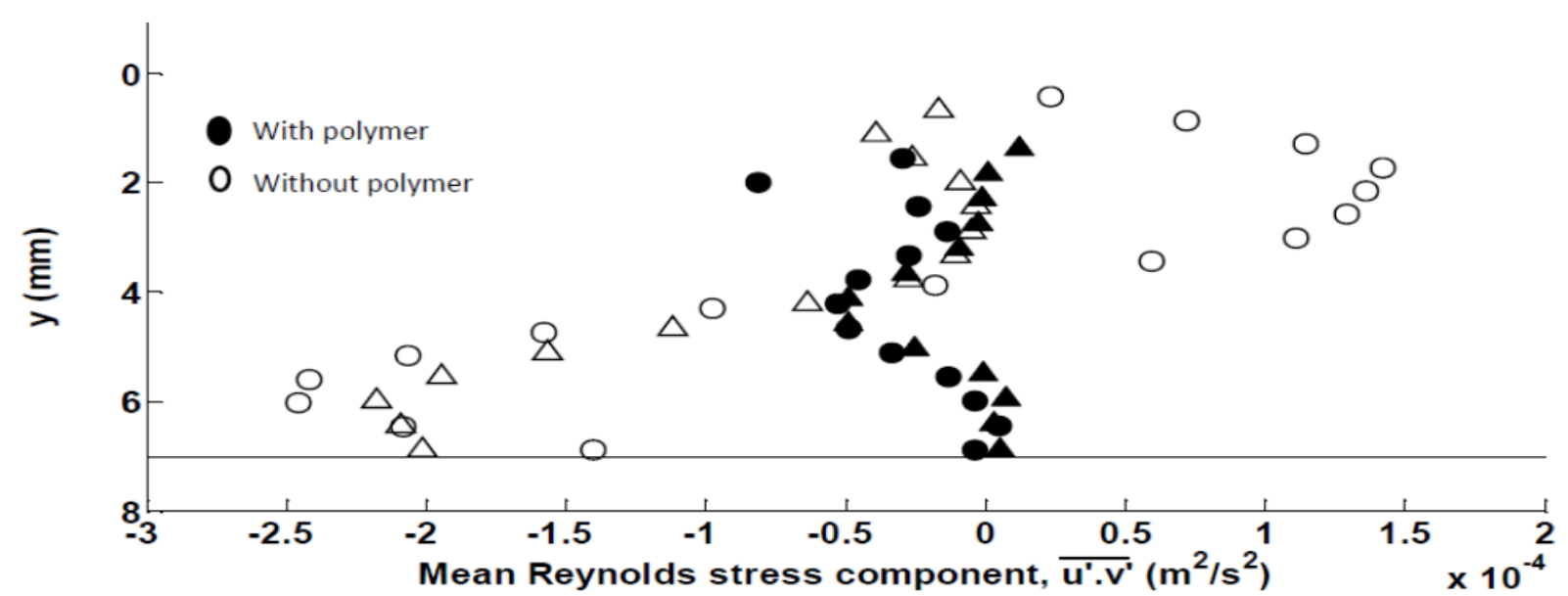

b) $\mathrm{Uso}=0.195 \mathrm{~m} / \mathrm{s} ; \mathrm{Usw}=0.166 \mathrm{~m} / \mathrm{s}$ (triangle) and Usw $=0.220 \mathrm{~m} / \mathrm{s}$ (circles)

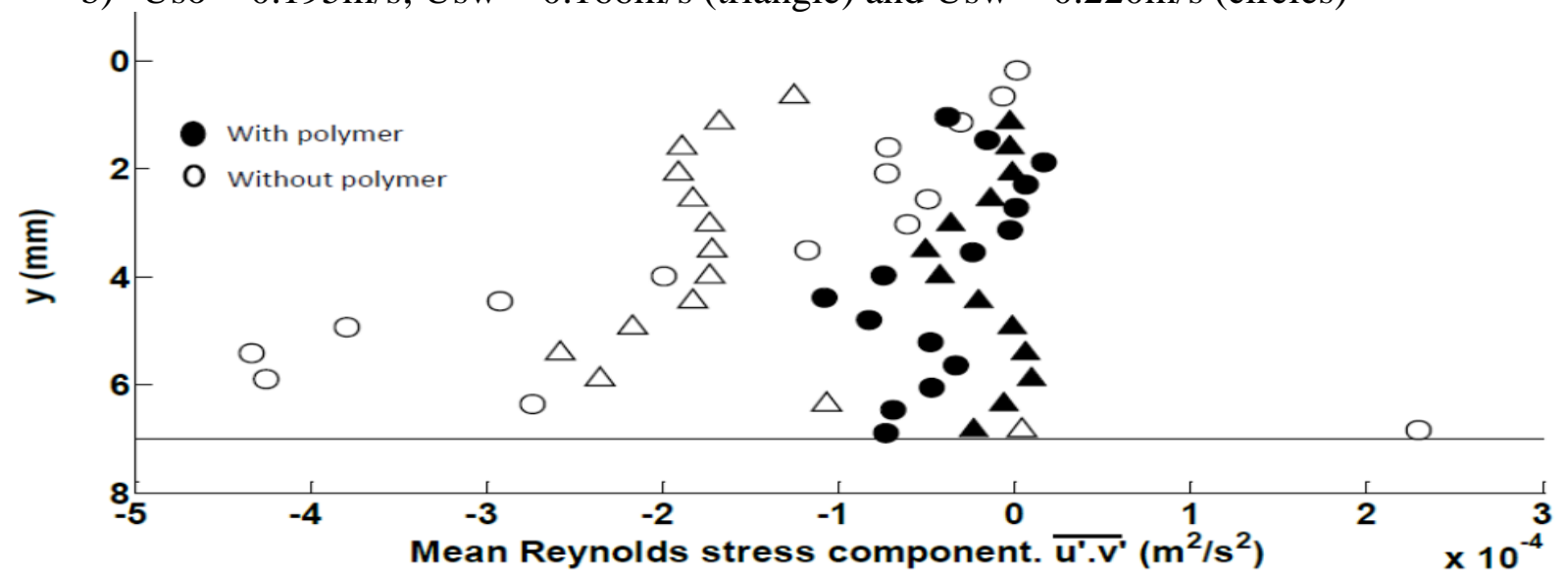

c) Uso $=0.245 \mathrm{~m} / \mathrm{s} ;$ Usw $=0.166 \mathrm{~m} / \mathrm{s}$ (triangle) and Usw $=0.220 \mathrm{~m} / \mathrm{s}$ (circles)

Fig. 7 Mean Reynolds stress tensor profiles in the water phase.

This observed reduction of the Reynolds stresses with polymers has been reported earlier for single phase water flows (Ptasinski and Hulsen, 2001; Warholic et al., 2001). A reduction in the Reynolds stresses indicates a decrease of turbulent axial momentum transfer in the radial direction (Gyr and Bewersdorff, 1995; Wei and Willmarth, 1992). However, the decrease in Reynolds stresses is not proportional to the measured drag reduction. 
The above findings support the proposed mechanism that drag reduction is not just a suppression of turbulence but it involves a redistribution of turbulent kinetic energy from the radial to the axial flow direction (White and Mungal, 2008; Brasseur et al., 2005; Den Toonder et al., 1997; Wei and Willmarth, 1992). As can be seen from Figs. 6 and 7 the turbulent momentum flux is sifignicantly reduced in the radial direction. At the same time, from Fig. 5 it is seen that the momentum flux is increased in the axial direction. According to Sher \& Hetsroni (2008), the polymer undergoes continuous stretching and relaxation which enables it to absorb energy intended for radial transport and dissipates it in the axial flow direction when it relaxes. In Newtonian flows, the high velocity gradients in the near-wall region lead to high production of turbulent eddies which are transported into the bulk flow in the radial direction against the desired axial flow direction. This leads to energy losses and increased pressure drop. When polymers are added, the reduction in the radial transport of turbulence leads to a decrease in energy losses and a corresponding enhancement of the axial flow (Fig. 4). This improved energy efficiency is measured as a reduction in the pressure drop (drag reduction) of the system. In cold regions where pipes are heated to prevent hydrate formation among other things, the reduction in momentum transfer from the wall to the bulk flow when polymers are added can reduce heat losses thereby reducing operational costs (Zhang et al., 2013; Wang et al., 2011; Vleggaar and Tels, 1973).

\subsection{Experiments with Polyethylene Oxide (PEO)}

It was found that compared to HPAM, the addition of 8MPEO in single phase water flow had similar effects while that of 5MPEO was different, as can be seen from the friction factor against Reynolds number graphs in von Karman coordinates (Fig. 8). In the same figure the maximum drag reduction asymptote (MDRA; Virk, 1975) and the Prandtl-Karman (P-K) line for Newtonian flows are also shown.

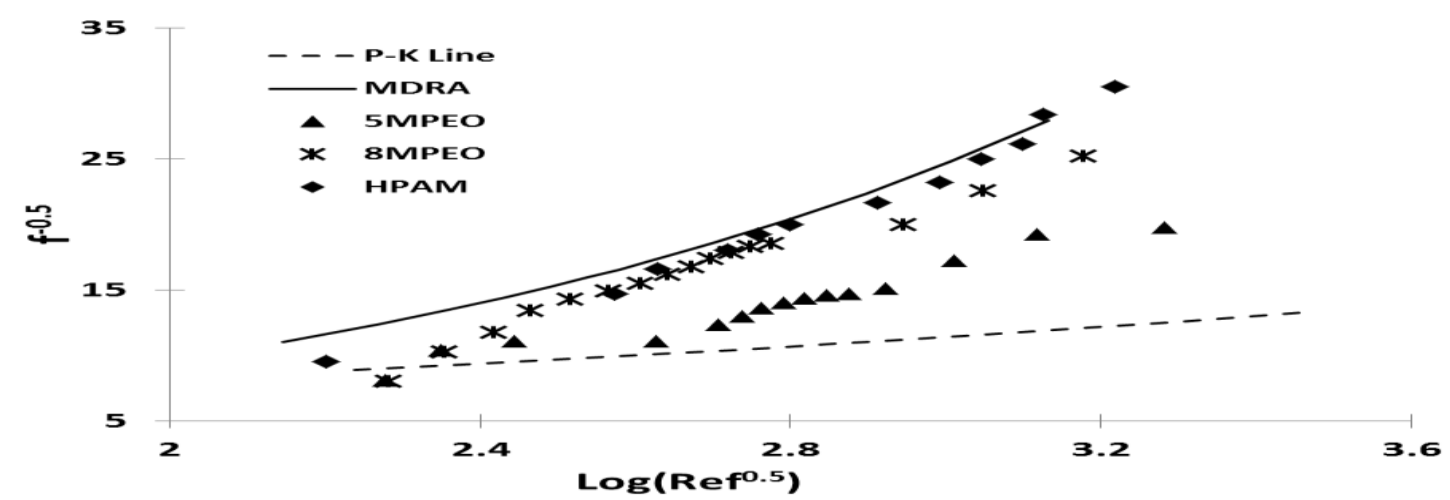

Fig. 8 Effect on friction factor of the addition of $20 \mathrm{ppm}$ of three polymers (HPAM, 5MPEO \& 8MPEO) in single phase water flow. The Newtonian flow and Virk's maximum drag reduction asymptote are also shown. 
The friction factor (f) is calculated from the measured pressure drop before and after polymer addition and is given by Eq. 9, while the theoretical friction factor (P-K line) and the MDRA lines are given by Eqs. $10 \& 11$ respectively:

$\Delta \mathrm{P}=\frac{2 \mathrm{flU}^{2} \rho}{\mathrm{D}}$

$\mathrm{f}=0.0792 \operatorname{Re}^{-0.25}$

$\mathrm{f}=0.58 \operatorname{Re}^{-0.58}$

With the addition of polymers to single phase water flow, friction factors significantly decrease for Reynolds numbers above 2000, where flow becomes turbulent. The maximum drag reduction obtained in this work with HPAM was about $80 \%$ for Reynolds numbers over 42,000, while with 8MPEO and 5MPEO it was about $70 \%$ and $55 \%$ respectively. Fig. 8 clearly shows that drag reduction increases with the polymer molecular weight. The polymer ionic structure can also be significant (Abdulbari et al., 2014; Al-Sarkhi, 2010) which may explain the similar values of friction factors between solutions of HPAM and 8MPEO even though they have different molecular weights, particularly at Reynolds numbers below 15,000. With PEO polymers, the decrease in friction factors becomes less steep at high Reynolds numbers (above 15,000) compared to HPAM. PEO polymers are prone to mechanical degradation at high Reynolds numbers (Wei and Willmarth, 1992) while HPAM has a higher resistance (Abubakar et al., 2014a; Den Toonder et al., 1995; Hoyt, 1986).

For the oil-water flows studied here and actual water Rew $<10,000$, the effects of 8MPEO and HPAM were found to be similar. Therefore, only comparisons between HPAM and 5MPEO will be shown. The different effects of HPAM and 5MPEO on the average axial water velocity profile and turbulence properties during oil-water flows can be seen in Fig. 9 to Fig. 12 for Uso $=0.150 \mathrm{~m} / \mathrm{s}$ and $\mathrm{Usw}=0.166 \mathrm{~m} / \mathrm{s}$. 


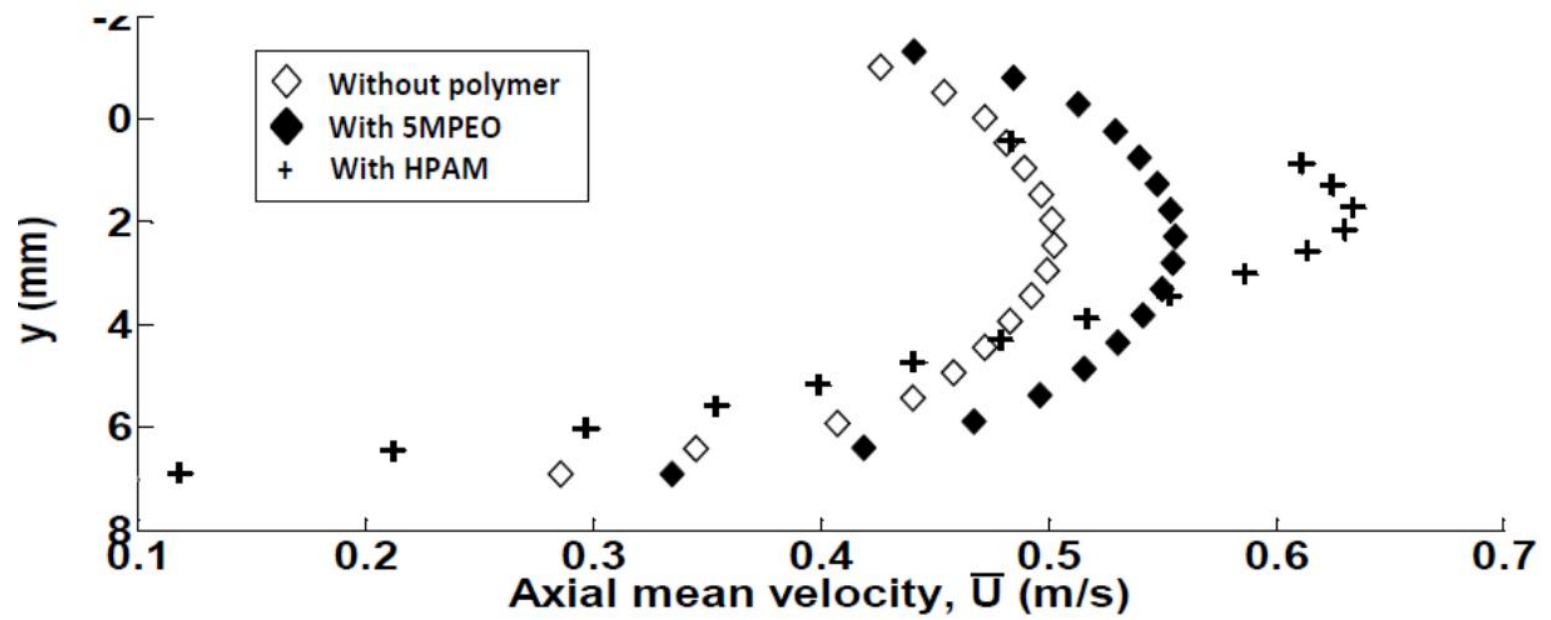

Fig. 9 Axial velocity profiles in the water phase for Newtonian and drag reduced oil-water flows. Uso $=0.150 \mathrm{~m} / \mathrm{s}$, Usw $=0.166 \mathrm{~m} / \mathrm{s}, 20 \mathrm{ppm}$ polymer concentration in the water phase.

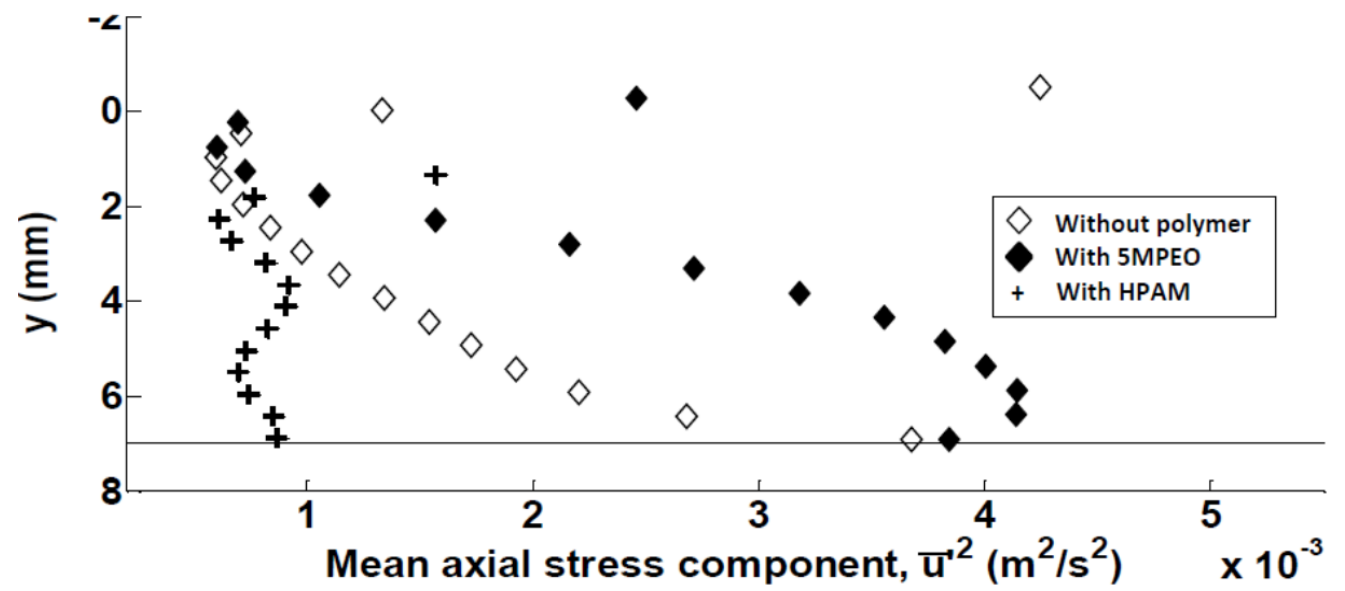

Fig. 10 Axial stress tensor profiles in the water phase for Newtonian and drag reduced oil-water flows. Uso $=0.150 \mathrm{~m} / \mathrm{s}$ and Usw $=0.166 \mathrm{~m} / \mathrm{s}, 20 \mathrm{ppm}$ polymer concentration in the water phase.

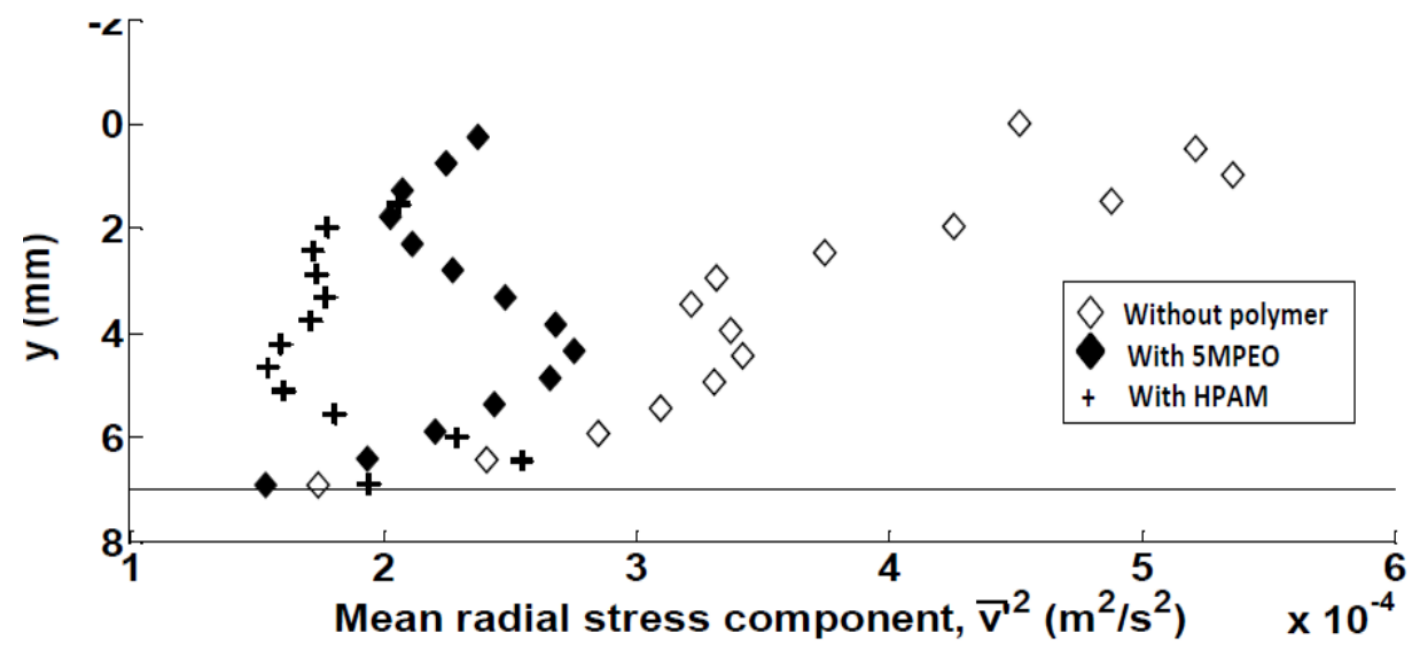

Fig. 11 Radial stress tensor profiles in the water phase for Newtonian and drag reduced oil-water flows. Uso $=0.150 \mathrm{~m} / \mathrm{s}$ and Usw $=0.166 \mathrm{~m} / \mathrm{s}, 20 \mathrm{ppm}$ polymer concentration in the water phase 


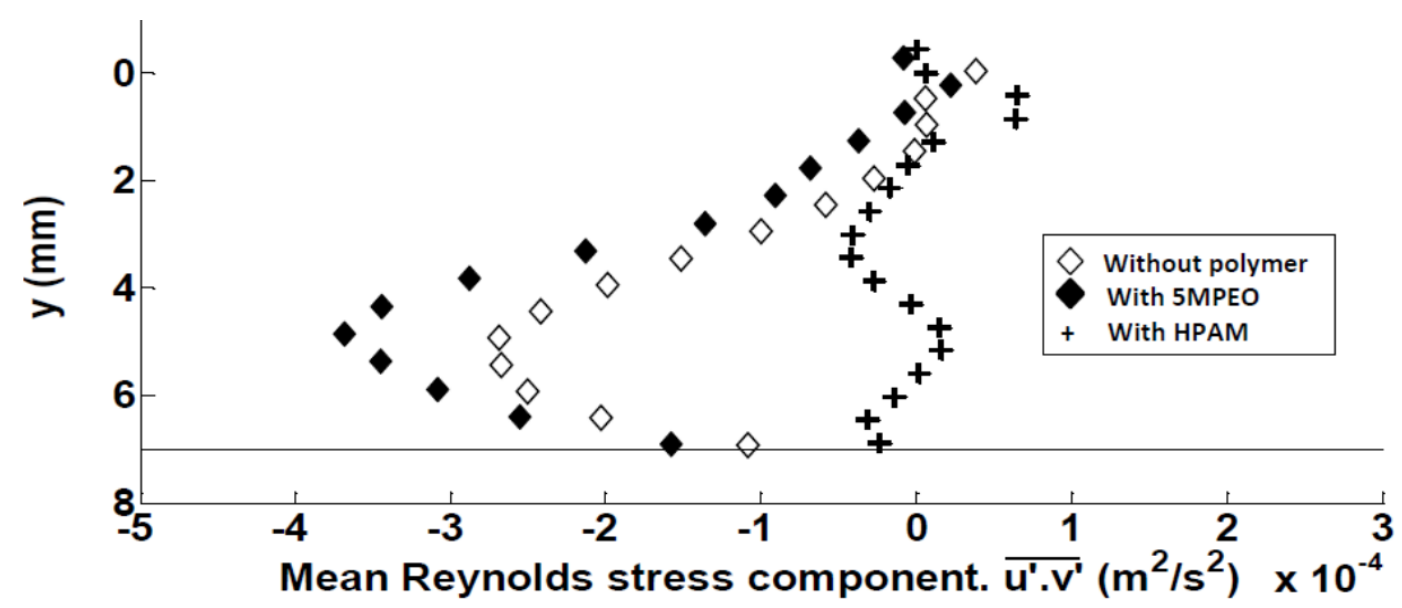

Fig. 12 Reynolds stress tensor profiles in the water phase for Newtonian and drag reduced oilwater flows. Uso $=0.150 \mathrm{~m} / \mathrm{s}$ and $\mathrm{Usw}=0.166 \mathrm{~m} / \mathrm{s}, 20 \mathrm{ppm}$ polymer concentration in the water phase

In general, the effect of 5MPEO on the flow is less than that of HPAM. When 5MPEO is added in the water phase, the maximum of the velocity increases but the profile does not change shape significantly (Fig. 9). With the addition of 5MPEO, the turbulent axial stresses and the absolute values of the Reynolds stresses increased compared to the flow without polymer, while they reduced when HPAM was added. The radial stress tensor was slightly reduced with 5MPEO compared to the flow without polymer but not as much as in the case of HPAM. The turbulent axial and Reynolds stress tensors also depend on the axial velocity gradient and are high in areas of large velocity gradient (shear) in the near wall region (Escudier et al., 2009; Scharnowski et al., 2010). The increase in the axial velocity gradient close to the wall (see Fig. 9) after the addition of 5MPEO leads to corresponding increase in the Reynolds and axial stress tensors, when compared to flows without polymer. The same trends were seen at the other Uso tested. At higher superficial oil and water velocities, Uso $>0.150 \mathrm{~m} / \mathrm{s}$ and Usw $>0.250 \mathrm{~m} / \mathrm{s}$ (not shown here) where the water phase Reynolds number was greater than 4000 there was some reduction in the axial and Reynolds stress tensors in the 5MPEO solution compared to flow without polymer but not as large as with the HPAM. This suggests that with low molecular weight polymers higher Reynolds numbers may be required to initiate drag reduction. Polymers with large molecular weights have high degree of chain entanglement and aggregate formation as well as higher hydrodynamic volume which enhance drag reduction (Abdulbari et al., 2014; AlSarkhi, 2010; Le Brun et al., 2016; Sellin et al., 1982; Virk, 1975; Zadrazil et al., 2012). They are also less susceptible to mechanical degradation compared to their lower molecular weight counterparts with the same chemical structure (Abubakar et al., 2014a). In addition, ionic polymers, such as HPAM, are known to be more effective drag reducing agents compared to non-ionic ones, such as the PEOs (Abubakar et al., 2014a). 


\section{CONCLUSIONS}

The effects of different polymers on the velocity and turbulent properties of oil-water two-phase flows have been studied using PIV. The polymers used were polyacrylamide (HPAM) and two types of polyethylene oxide (PEO) with different molecular weights. Investigations were carried out in the stratified and stratified wavy flow regimes, where the following were found:

- The addition of polymer increased the average and the maximum velocities of the water phase of the two-phase flow. The axial velocity profile became more parabolic signifying laminarization of the flow in the water layer.

- Turbulence properties of the flows were significantly affected by the addition of polymer to the water phase. With the HPAM, Reynolds and radial stress tensors were reduced throughout the pipe section while the axial stress tensor was reduced close to the wall and the interface but increased in the bulk flow. The results with the PEO depended on the molecular weight.

- The changes in the turbulent stresses after the addition of polymer support the proposed mechanism that drag reduction results in the redistribution of the turbulent kinetic energy from the radial to the axial flow direction which is measured as a reduction in the pressure drop of the system.

- Drag reduction increased with the molecular weight of the polymers used. Polymer ionic strength and mechanical degradation at high Reynolds numbers also affected the degree of drag reduction.

\section{ACKNOWLEDGEMENTS}

L.C. Edomwonyi-Otu would like to thank the Petroleum Technology Development Fund (PTDF) Nigeria for his $\mathrm{PhD}$ studentship. The authors would like to acknowledge the UK EPSRC Engineering Instrument Pool for the loan of the PIV system and the high-speed camera, and Dr Maxime Chinaud for support with the PIV measurements. The authors would also like to thank Dr Simon Barrass for his technical assistance with the conductivity probes.

\section{REFERENCES}

Abdulbari, H.A., Shabirin, A., Abdurrahman, H.N., 2014. Bio-polymers for improving liquid flow in pipelines-A review and future work opportunities. J. Ind. Eng. Chem. 20, 11571170.

Abubakar, A., Al-Hashmi, A.., Al-Wahaibi, T., Al-Wahaibi, Y., Al-Ajmi, A., Eshrati, M., 
2014a. Parameters of Drag Reducing Polymers and Drag Reduction Performance in SinglePhase Water Flow. Adv. Mech. Eng. 2014, 1-8.

Abubakar, A., Al-Wahaibi, T., Al-Hashmi, A.R., Al-Wahaibi, Y., Al-Ajmi, A., Eshrati, M., 2015. Influence of drag-reducing polymer on flow patterns, drag reduction and slip velocity ratio of oil-water flow in horizontal pipe. Int. J. Multiph. Flow 73, 1-10.

Abubakar, A., Al-Wahaibi, T., Al-Wahaibi, Y., Al-Hashmi, A.R., Al-Ajmi, A., 2014b. Roles of drag reducing polymers in single- and multi-phase flows. Chem. Eng. Res. Des. 92, 21532181.

Adrian, R.J., Westerweel, J., 2011. Particle Image Velocimetry, illustrate. ed. Cambridge University Press.

Al-Sarkhi, A., 2010. Drag reduction with polymers in gas-liquid/liquid-liquid flows in pipes: A literature review. J. Nat. Gas Sci. Eng. 2, 41-48.

Al-Sarkhi, A., Abu-Nada, E., Batayneh, M., 2006. Effect of drag reducing polymer on air-water annular flow in an inclined pipe. Int. J. Multiph. Flow 32, 926-934.

Al-Sarkhi, A., Soleimani, A., 2004. Effect of drag reducing polymers on two-phase gas -liquid flows in a horizontal pipe. Chem. Eng. Res. Des. 82, 1583-1588.

Al-Wahaibi, T., Smith, M., Angeli, P., 2007. Effect of drag-reducing polymers on horizontal oil-water flows. J. Pet. Sci. Eng. 57, 334-346.

Al-Wahaibi, T., Yusuf, N., Al-Wahaibi, Y., Al-Ajmi, A., Al-Hashmi, A.R., Olawale, A.S., Mohammed, I.A., 2012. Experimental study on the effect of drag reducing polymer on flow patterns and drag reduction in a horizontal oil-water flow. Int. J. Heat Fluid Flow 37, 7480.

Al-Yaari, M., Al-Sarkhi, A., Abu-Sharkh, B., 2012. Effect of drag reducing polymers on water holdup in an oil-water horizontal flow. Int. J. Multiph. Flow 44, 29-33.

Al-Yaari, M., Soleimani, A., Abu-Sharkh, B., Al-Mubaiyedh, U., Al-Sarkhi, A., 2009. Effect of drag reducing polymers on oil-water flow in a horizontal pipe. Int. J. Multiph. Flow 35, 516-524.

Baik, S., Hanratty, T.J., 2003. Effects of a drag reducing polymer on stratified gas-liquid flow in a large diameter horizontal pipe. Int. J. Multiph. Flow 29, 1749-1757.

Barral, A.H., Angeli, P., 2013. Interfacial characteristics of stratified liquid-liquid flows using a conductance probe. Exp. Fluids 54, 1604:1-15.

Birvalski, M., Tummers, M.J., Delfos, R., Henkes, R.A.W.M., 2014. PIV measurements of waves and turbulence in stratified horizontal two-phase pipe flow. Int. J. Multiph. Flow 62, $161-173$.

Birvalski, M., Tummers, M.J., Delfos, R., Henkes, R.A.W.M., 2013. PIV measurements of waves and turbulence in stratified horizontal two-phase pipe flow, in: The 16th International Conference on Multiphase Production Technology. BHR Group, Cannes, France, pp. 337-351.

Brasseur, J.G., Robert, A., Collins, L.R., Vaithianathan, T., 2005. Fundamental Physics Underlying Polymer Drag Reduction, from Homogeneous DNS Turbulence with the FENE-P Model 23-26.

Chaouki, J., Farcal, L., Milorad, P.D., 1997. Noninvasive Tomographic and Velocimetric Monitoring of Multiphase Flows. Ind. Eng. Chem. Res 36, 4476-4503.

Cheung, T.K., Street, R.L., 1988. The turbulent layer in the water at an air-water interface. J. 
Fluid Mech. 194, 133-151.

Chinaud, M., Park, K.H., Angeli, P., 2017. Flow pattern transition in liquid-liquid flows with a transverse cylinder. Int. J. Multiph. Flow 90, 1-12.

Cohen, L.S., Hanratty, T.J., 1968. Effect of waves at a gas-liquid interface on a turbulent air flow. J. Fluid Mech. 31, 467-479

Cowen, E.A., 2015. Canonical turbulent flows. In: Turbflow. Chapter 2, 9-19.

Den Toonder, J.M.J., Draad, A.A., Kuiken, G.D.C., Nieuwstadt, F.T.M., 1995. Degradation effects of dilute polymer solutions on turbulent drag reduction in pipe flows. Appl. Sci. Res. 55, 63-82.

Den Toonder, J.M.J., Hulsen, M.A., Kuiken, G.D.C., Nieuwstadt, F.T.M., 1997. Drag reduction by polymer additives in a turbulent pipe flow: numerical and laboratory experiments. J. Fluid Mech. 337, 193-231.

Edomwonyi-Otu, L.C., Adelakun D.O., 2018. Effects of heavy molecular weight polymer on quality of drinking water. Materials Today Communications (15), 337-343

Edomwonyi-Otu, L.C., Angeli, P., 2014. Effects of polymer addition on pressure drop and interfacial waves in horizontal oil-water flows. Petroleum Technology Development Journal 2 (July), 41-48

Edomwonyi-Otu, L.C; Chinaud, M; Angeli, P. 2014. Drag reduction in oil-water flows. SPE Journal-OnePetro 2014-C2-BHR Publishers

Edomwonyi-Otu, L.C., Angeli, P., 2015. Pressure drop and holdup predictions in horizontal oilwater flows for curved and wavy interfaces. Chem. Eng. Res. Des. 93, 55-65.

Edomwonyi-Otu, L.C., Chinaud, M., Angeli, P., 2015. Effect of drag reducing polymer on horizontal liquid-liquid flows. Exp. Therm. Fluid Sci. 64, 164-174.

Escudier, M.P., Rosa, S., Poole, R.J., 2009. Asymmetry in transitional pipe flow of dragreducing polymer solutions. J. NonNewtonian. Fluid Mech. 161, 19-29.

Gyr, A., Bewersdorff, H.W., 1995. Drag reduction of turbulent flows with additives. The Netherlands Kluwer Academic Publishers, Dordrecht.

Hanratty, T.J., Al-Sarkhi, A., 2001. Effect of drag-reducing polymers on annular gas - liquid flow in a horizontal pipe. Int. J. Multiph. Flow 27, 1151-1162.

Hoyt, J.W., 1986. Drag Reduction, in: Mark HF et al (Eds) Encyclopedia of Polymer Science and Engineering. John Wiley \& Sons, New York, USA, pp. 129-151.

Kang, C., Jepson, W.P., Gopal, M., 1998. The effect of drag reducing agents on corrosion in multiphase flow, in: Corrosion' 98. p. 54:1-11.

Kumara, W.A.S., Elseth, G., Halvorsen, B.M., Melaaen, M.C., 2010a. Comparison of Particle Image Velocimetry and Laser Doppler Anemometry measurement methods applied to the oil-water flow in horizontal pipe. Flow Meas. Instrum. 21, 105-117.

Kumara, W.A.S., Halvorsen, B.., Melaaen, M.., 2009. Velocity and turbulence measurements of oil- water flow in horizontal and slightly inclined pipes using PIV 1-16.

Kumara, W.A.S., Halvorsen, B.M., Melaaen, M.C., 2010b. Particle image velocimetry for characterizing the flow structure of oil-water flow in horizontal and slightly inclined pipes. Chem. Eng. Sci. 65, 4332-4349.

Le Brun, N., Zadrazil, I., Norman, L., Bismarck, A., Markides, C.N., 2016. On the drag reduction effect and shear stability of improved acrylamide copolymers for enhanced hydraulic fracturing. Chem. Eng. Sci. 146, 135-143. 
Manfield, C.J., Lawrence, C., Hewitt, G., 1999. Drag-reduction with additive in multiphase flow: a literature survey. Multiph. Sci. Technol. 11, 197-221.

Morgan, R.G., Ibarra, R., Zadrazil, I., Matar, O.K., Hewitt, G.F., Markides, C.N., 2017. On the role of buoyancy-driven instabilities in horizontal liquid-liquid flow. Int. J. Multiph. Flow $89,123-135$.

Morgan, R.G., Markides, C.N., Hale, C.P., Hewitt, G.F., 2012. Horizontal liquid-liquid flow characteristics at low superficial velocities using laser-induced fluorescence. Int. J. Multiph. Flow 43, 101-117.

Morgan, R.G., Markides, C.N., Zadrazil, I., Hewitt, G.F., 2013. Characteristics of horizontal liquid-liquid flows in a circular pipe using simultaneous high-speed laser-induced fluorescence and particle velocimetry. Int. J. Multiph. Flow 49, 99-118.

Mowla, D., Naderi, A., 2006. Experimental study of drag reduction by a polymeric additive in slug two-phase flow of crude oil and air in horizontal pipes. Chem. Eng. Sci. 61, 15491554.

Nieuwenhuys, G.M.., 2003. Effect of Drag-Reducing Polymers on a Vertical Multiphase Flow by G.M . H . MEAH: 230. MEAH $2301-51$.

Ptasinski, P.., Hulsen, M.., 2001. Experiments in Turbulent Pipe Flow with Polymer Additives at Maximum Drag Reduction. Flow, Turbul. Combust. 66, 159-182.

Rosehart, R.G., Scott, D., Rhodes, E., 1972. Gas-liquid slug flow with drag reducing polymer solutions. AIChE J. 18, 744-750.

Scharnowski, S., Hain, R., Kähler, C.J., 2010. Estimation of Reynolds Stresses from PIV Measurements with Single-Pixel Resolution, in: 15th Int Symp on Applications of Laser Techniques to Fluid Mechanics. Lisbon, pp. 5-8.

Schmitt, F.G., 2008. About Boussinesq $\square$ s turbulent viscosity hypothesis : historical remarks and a direct evaluation of its validity. Comptes Rendus Mec. Elsevier 335, 617-627.

Sedahmed, G.H., Abdo, M.S.E., Amer, M., El-Latif, G.A., 1999. Effect of drag reducing polymers on the rate of mass transfer controlled corrosion in pipelines under developing turbulent flow. Int. Commun. heat mass Transf. 26, 531-538.

Sellin, R.H.J., Hoyt, J.W., Scrivener, O., 1982. The effect of drag-reducing additives on fluid flows and their industrial applications. Part 1: Basic aspects. J. Hydraul. Res. 20, 29-68.

Sher, I., Hetsroni, G., 2008. A mechanistic model of turbulent drag reduction by additives. Chem. Eng. Sci. 63, 1771-1778.

Virk, P.S., 1975. Drag Reduction Fundamentals. AlChE J. 21, 625-656.

Vleggaar, J., Tels, M., 1973. Heat transfer in a heterogeneous drag reduction system. Int. J. Heat Mass Transf. 16, 1629-1631.

Voulgaropoulos V., Angeli P. 2017. Optical measurements in evolving dispersed pipe flows. Experiments in Fluids, 58, 170.

Wang, Y., Yu, B., Zakin, J.L., Shi, H., 2011. Review on Drag Reduction and Its Heat Transfer by Additives. Adv. Mech. Eng., 1-17.

Warholic, M.D., Heist, D.K., Katcher, M., Hanratty, T.J., 2001. A study with particle-image velocimetry of the influence of drag-reducing polymers on the structure of turbulence. Exp. Fluids 31, 474-483.

Warholic, M.D., Massah, H., Hanratty, T.J., 1999. Influence of drag-reducing polymers on 
turbulence: effects of Reynolds number, concentration and mixing. Exp. Fluids 27, 461472.

Wei, T., Willmarth, W.W., 1992. Modifying turbulent structure with drag-reducing polymer additives in turbulent channel flows. J. Fluid Mech. 245, 619-641.

Westerweel, J., 1997. Fundamentals of digital particle image velocimetry. Meas. Sci. Technol. 8, 1379-1392.

White, C., Mungal, M.G., 2008. Mechanics and prediction of turbulent drag reduction with polymer additives. Annu. Rev. Fluid Mech. 40, 235-256.

White, C.M., Somandepalli, V.S.R., Mungal, M.G., 2004. The turbulence structure of dragreduced boundary layer flow. Exp. Fluids 36, 62-69.

Zadrazil, I., Bismarck, A., Hewitt, G.F., Markides, C.N., 2012. Shear layers in the turbulent pipe flow of drag reducing polymer solutions. Chem. Eng. Sci. 72, 142-154.

Zadrazil, I., Markides, C.N., 2014. A mechanism of polymer induced drg reduction in turbulent pipe flow, in: 10th International Conference on Heat Transfer, Fluid Mechanics and Thermodynamics. Orlando, Florida, pp. 1-7.

Zahran, R.R., Sedahmed, G.H., 1998. Effect of drag-reducing polymers on the rate of flowinduced corrosion of metals. Mater. Lett. 35, 207-213.

Zhang, J., Childress, S., Libchaber, A., 1998. Non-Boussinesq effect: Asymmetric velocity profiles in thermal convection. Phys. Fluids 10, 1534.

Zhang, X., Liu, L., Cheng, L., Guo, Q., Zhang, N., 2013. Experimental study on heat transfer and pressure drop characteristics of air-water two-phase flow with the effect of polyacrylamide additive in a horizontal circular tube. Int. J. Heat Mass Transf. 58, 427440.

Zhou, X., Doup, B., Sun, X., 2013. Measurements of liquid-phase turbulence in gas-liquid twophase flows using particle image velocimetry. Meas. Sci. Technol. 24, 125303. 